NATIONAL LABORATORY

\title{
ANNUAL TECHNICAL PROGRESS REPORT OF THE RADIOISOTOPE POWER SYSTEMS MATERIALS PRODUCTION AND TECHNOLOGY PROGRAM TASKS FOR OCTOBER 1, 2008 THROUGH SEPTEMBER 30, 2009
}

May 2010

Prepared by

J. F. King

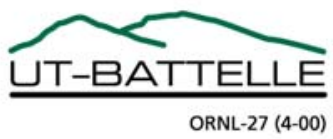




\title{
DOCUMENT AVAILABILITY
}

Reports produced after January 1, 1996, are generally available free via the U.S. Department of Energy (DOE) Information Bridge.

Web site http://www.osti.gov/bridge

Reports produced before January 1, 1996, may be purchased by members of the public from the following source.

\author{
National Technical Information Service \\ 5285 Port Royal Road \\ Springfield, VA 22161 \\ Telephone 703-605-6000 (1-800-553-6847) \\ TDD 703-487-4639 \\ Fax 703-605-6900 \\ E-mail info@ntis.gov \\ Web site http://www.ntis.gov/support/ordernowabout.htm
}

Reports are available to DOE employees, DOE contractors, Energy Technology Data Exchange (ETDE) representatives, and International Nuclear Information System (INIS) representatives from the following source.

Office of Scientific and Technical Information

P.O. Box 62

Oak Ridge, TN 37831

Telephone 865-576-8401

Fax 865-576-5728

E-mail reports@osti.gov

Web site http://www.osti.gov/contact.html

This report was prepared as an account of work sponsored by an agency of the United States Government. Neither the United States Government nor any agency thereof, nor any of their employees, makes any warranty, express or implied, or assumes any legal liability or responsibility for the accuracy, completeness, or usefulness of any information, apparatus, product, or process disclosed, or represents that its use would not infringe privately owned rights. Reference herein to any specific commercial product, process, or service by trade name, trademark, manufacturer, or otherwise, does not necessarily constitute or imply its endorsement, recommendation, or favoring by the United States Government or any agency thereof. The views and opinions of authors expressed herein do not necessarily state or reflect those of the United States Government or any agency thereof. 
Radioisotope Power Systems Materials Production and Technology Program Materials Science and Technology Division

\title{
ANNUAL TECHNICAL PROGRESS REPORT OF RADIOISOTOPE POWER SYSTEMS MATERIALS PRODUCTION AND TECHNOLOGY PROGRAM \\ TASKS FOR OCTOBER 1, 2008 THROUGH SEPTEMBER 30, 2009
}

\author{
J. F. King
}

May 2010

Prepared for

Department of Energy, Office of Space and Defense Power Systems

AF 0110100

Prepared by

OAK RIDGE NATIONAL LABORATORY

Oak Ridge, Tennessee 37831-6079

managed by

UT-BATTELLE, LLC

for the

U.S. DEPARTMENT OF ENERGY

under contract DE-AC05-00OR22725 



\section{CONTENTS}

Page

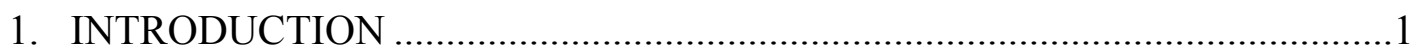

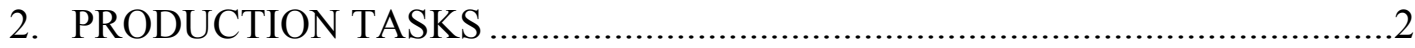

2.1 CARBON-BONDED CARBON FIBER ...............................................2

2.1.1 Background .........................................................................2

2.1.2 CBCF Production....................................................................2

2.1.3 CBCF Specifications, Production, and Qualification

Procedures............................................................................2

2.1.4 CBCF Production and Qualification Capability ...........................

2.2 IRIDIUM ALLOY BLANK AND FOIL PRODUCTION .........................

2.2.1 Blank Production ...................................................................... 3

2.2.2 Qualification of Upgraded Control System for Vacuum Arc

Remelting Furnace for Melting of Iridium Alloys.......................4

2.2.2.1 Background ...............................................................4

2.2.2.2 Procedure ...............................................................4

2.2.2.3 Results.....................................................................

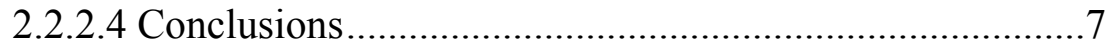

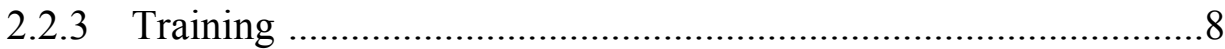

2.2.4 Chemical Analysis ............................................................ 8

2.2.4.1 Qualification of Alternate Source for Oxygen Analysis by Inert Gas Fusion...................................................... 8

2.2.4.2 Glow Discharge Mass Spectrometry …........................11

2.2.5 Deviation Requests ................................................................ 11

2.2.6 Equipment Major Maintenance and Purchases...........................11

2.2.7 Publications and Presentations.................................................12

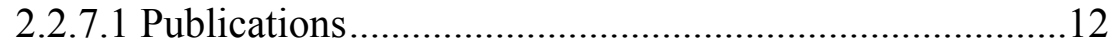

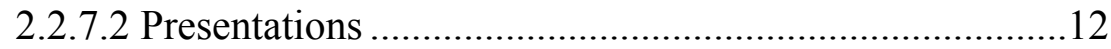

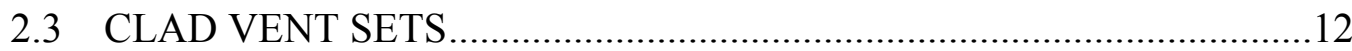

2.3.1 Maintenance Production Summary............................................12

2.3.2 Nonconformance Reports .................................................13

2.3.3 Deviation Requests ............................................................ 14

2.3.4 Qualification of Mahr Federal MarForm MMQ 400 Form

Measuring Instrument for CVS Cup Roundness and Flatness

Inspections - Milestone 2.C.4.............................................. 14

2.3.5 Decontamination Cover Tooling...........................................15

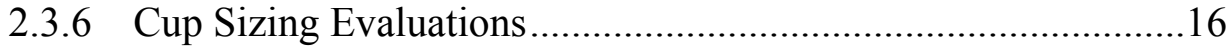

2.3.7 Frit Vent Tooling Evaluation ..................................................16

2.3.8 Metallurgical Destructive Test Sample Evaluations of Grit Blasted Versus Non-Grit Blasted Iridium Alloy Clad Vent Set Cup Surfaces. 
2.4 IRIDIUM POWDER AND INVENTORY MANAGEMENT .................23

2.4.1 Iridium Demand and Supply Schedule ....................................23

2.4.2 Annual Write-Off...................................................................24

2.4.3 Iridium Accountability Reviews ...........................................24

2.5 WELDING ........................................................................... 25

2.5.1 Russian Fuel Procurement and Radioactive Material

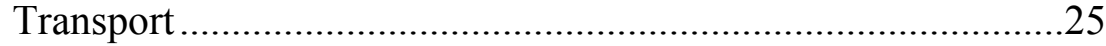

2.5.2 CVS Production Welding Support.........................................25

2.5.3 Weld Shield Qualification....................................................26

2.5.4 Qualification of Electron Beam Operators ..............................28

2.5.5 FY 2009 Fuel Procurement ...................................................28

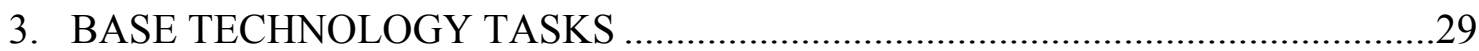

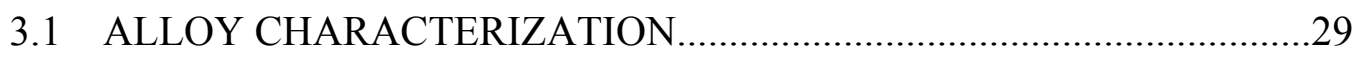

3.1.1 Introduction..................................................................29

3.1.2 Effects of Grain Size and Temperature on the Ductility and Strength of DOP-26 Iridium at a Low Strain Rate..............29

3.1.3 Effects of Tantalum on the Tensile Impact Ductility and Fracture Behavior of DOP-26 Iridium ....................................29

3.1.4 Evaluation of Silicon Contamination Effects in

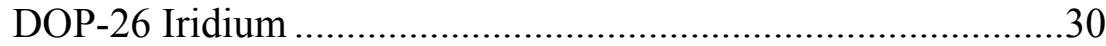

3.2 ORNL Characterization of Min-K TE-1400 ...........................................31

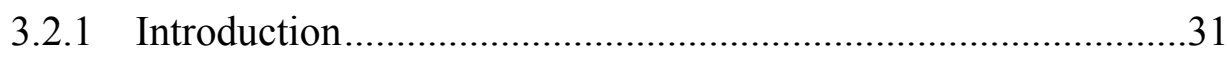

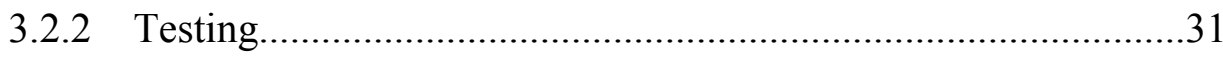

3.2.2.1 Task 1 Changing Environments Testing........................31

3.2.2.2 Task 2 Lateral Load Testing .........................................32

3.2.2.3 Task 3 Isothermal Stress Relaxation Testing .................35

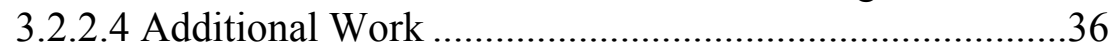




\section{LIST OF FIGURES}

Figure

Page

1 Surface of RS17 iridium alloy scrap ingot............................................. 5

$2 \quad$ RS17 iridium scrap ingot and electrode stub ................................................ 6

3 Chart recording of melting conditions of iridium scrap ingot RS17 shows initial leak rate test of the furnace followed by melting of the ingot. The arc current in amps (green) ramps to 3000 amps and is later ramped to 1800 amps. Arc voltage (red), vacuum (blue), and position (purple) are also shown

Prom computer control system of melting conditions of iridium scrap ingot RS17 shows arc current in amps (yellow), arc voltage and arc voltage set point (blue), and position (green)

5 Backscattered electron image (10X mag.) of ATJ graphite Pin \#5 showing residual iridium powder from lot 21, 012800, Jar A adhering to over half of Pin face after removal of bulk powder

6 Secondary electron image (400X mag.) of ATJ graphite Pin \#5 showing residual iridium powder from lot 21, 012800, Jar A adhering to Pin face in porous regions after removal of bulk powder

7 Secondary electron image (1000X magnification) of ATJ graphite Pin \#5 showing residual iridium powder from lot 21, 012800, Jar A adhering to Pin face in porous regions after removal of bulk powder.

8 Secondary electron image (10X magnification) of POCO AXF-5Q graphite Pin \#3 showing residual iridium powder from lot 21, 012800, Jar A adhering to Pin face

9 Secondary electron image (100X magnifaction) of POCO AXF-5Q graphite Pin \#3 showing residual iridium powder from lot 21, 012800, Jar A adhering to Pin face

10 Secondary electron image (400X magnification) of POCO AXF-5Q graphite Pin \#3 showing residual iridium powder from lot 21, 012800, Jar A adhering to Pin face

11 Secondary electron image (1000X magnification) of POCO AXF-5Q graphite Pin \#3 showing residual iridium powder from lot 21, 012800, Jar A adhering to Pin face

12 Secondary electron image (2000X magnification) of POCO AXF-5Q graphite Pin \#3 showing residual iridium powder from lot 21, 012800, Jar a adhering to Pin face

13 Cross section of weld shield butt weld ................................................... 27

14 Top view of completed weld shield butt weld ......................................... 27

15 Changing Environments Test \# 1_3 ..................................................... 32

16 Lateral load test set-up ..................................................................... 33

17 Test system for modification to accomplish lateral load testing................... 33

18 Lateral load test set-up (shown without furnace assembly)........................ 34

19 Room temperature lateral load test data.................................................... 34

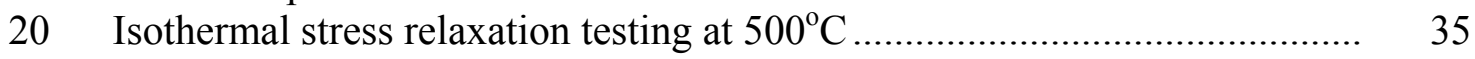





\section{LIST OF TABLES}

Table

Page

1 Comparison of Average Oxygen Analyses (ppm) by Y-12 and Leco for Solid Reference Materials .

2 Comparison of Average Oxygen Analyses (ppm) by Y-12 and Leco for Powder Reference Materials

3 Demand and Supply Schedule Shows Factors and Provides Strategy to Ensure an Adequate Supply of Iridium Powder for NASA Space Explorations and Defense Missions

$4 \quad$ Flow Testing of FVAs 26 



\section{ACRONYMS}

$\begin{array}{ll}\text { CBCF } & \text { Carbon-Bonded Carbon Fiber } \\ \text { CVS } & \text { Clad Vent Set } \\ \text { DAQ } & \text { data acquisition } \\ \text { DOE } & \text { Department of Energy } \\ \text { EB } & \text { electron beam } \\ \text { EDM } & \text { electro discharge machined } \\ \text { EDS } & \text { energy dispersive x-ray spectroscopy } \\ \text { EUO } & \text { engineering use only } \\ \text { FY } & \text { fiscal year } \\ \text { INL } & \text { Idaho National Laboratory } \\ \text { LANL } & \text { Los Alamos National Laboratory } \\ \text { NASA } & \text { National Aeronautics and Space Administration } \\ \text { ORNL } & \text { Oak Ridge National Laboratory } \\ \text { NCR } & \text { nonconformance reports } \\ \text { QA } & \text { quality assurance } \\ \text { RPS } & \text { Radioisotope Power Systems } \\ \text { RTG } & \text { radioisotope thermoelectric generators } \\ \text { SEM } & \text { scanning electron microscope } \\ \text { VAR } & \text { vacuum arc remelting } \\ \text { VCA } & \text { vent cup assemblies } \\ \text { VMM } & \text { vision measuring machine }\end{array}$





\title{
ANNUAL TECHNICAL PROGRESS REPORT OF RADIOISOTOPE POWER SYSTEMS MATERIALS PRODUCTION AND TECHNOLOGY PROGRAM \\ TASKS FOR OCTOBER 1, 2008 THROUGH SEPTEMBER 30, 2009*
}

\author{
J. F. King
}

\subsection{INTRODUCTION}

The Office of Space and Defense Power Systems of the U. S. Department of Energy (DOE) provides Radioisotope Power Systems (RPS) for applications where conventional power systems are not feasible. For example, radioisotope thermoelectric generators (RTG) were supplied by the DOE to the National Aeronautics and Space Administration (NASA) for deep space missions including the Cassini Mission launched in October of 1997 to study the planet Saturn. For the Cassini Mission, the Oak Ridge National Laboratory (ORNL) produced carbon-bonded carbon fiber (CBCF) insulator sets, iridium alloy blanks and foil, and clad vent sets (CVS) used in the generators. ORNL has been involved in developing materials and technology and producing components for the DOE for more than three decades.

This report reflects program guidance from the Office of Space and Defense Power Systems for fiscal year (FY) 2009. Production activities for prime quality (prime) CBCF insulator sets, iridium alloy blanks and foil, and CVS are summarized in this report. Technology activities are also reported that were conducted to improve the manufacturing processes, characterize materials, or to develop information for new RPS.

*Research sponsored by the U.S. Department of Energy, Office of Space and Defense Power Systems, under contract with UT-Battelle, LLC. 


\subsection{PRODUCTION TASKS}

\subsection{CARBON-BONDED CARBON FIBER}

\subsubsection{Background}

The CBCF production facilities have been operated in a production maintenance mode since the Cassini campaign to produce prime quality insulators. Dedicated facilities for CBCF production remain in the Carbon Materials Technology Laboratory at ORNL. During much of the 1990s CBCF production was directed at making experimental variations of $\mathrm{CBCF}$ that explored the potential for improved insulating attributes at very high temperatures. The effect of brief excursions to reentry temperatures was also explored. Sleeves produced in FY 2000 were the first to be fully characterized in nearly a decade. Resolution of issues related to elevated impurities in CBCF allowed for continued production of Prime Quality insulators in FY 2003-2008. Prime Quality insulation sets were shipped to the Idaho National Laboratory (INL) in FY 2006-2008 to support the Mars Science Laboratory Mission. Production of prime quality insulators continued in FY 2009 while implementing upgrades to production equipment and revision of numerous specifications and procedures.

\subsubsection{CBCF Production}

Twenty additional prime candidate CBCF insulation sleeves were produced in FY 2009 to support future RPS Program missions. Failure of the electronic flow controller on the vacuum molding system precluded the production of CBCF plates for discs in FY 2009. A new flow controller was installed and calibrated by the close of the FY. A revised procedure will be developed in the first quarter of FY 2010 while making development runs of CBCF plates and sleeves. Numerous Quality Assurance (QA) Surveillances were conducted at ORNL including: instrument calibration, dimensional inspection of insulators, personnel training, and various production activities.

\subsubsection{CBCF Specifications, Production, and Qualification Procedures}

A total of eight CBCF Specifications, Production Procedures, and Qualification Procedures were revised including the following:

MET-CER-MS-11, Specification for Chopping of Rayon Fiber

MET-CER-MS-13, Specification for Procurement of Rayon Tow

MET-CER-MS-14, Specification for Procurement of Phenolic Resin Powder

MET-CER-SOP-29, Preparation of Carbon Fiber

MET-CER-SOP-30, Slurry Preparation

MET-CER-SOP-35, Sieving Phenolic Resin Powder

MET-CER-SOP-37, Machining of CBCF Insulators

MET-CER-SOP-40, Compressive Strength Measurement on CBCF Insulation 


\subsubsection{CBCF Production and Qualification Capability}

Key personnel including the task manager, two principal technicians, and two machinists remain committed to the near-term ( $\sim 5$ years) production of CBCF insulators. A backup inspector is in training in the dimensional and visual inspection of CBCF insulators and qualification specimens. Additionally, personnel involved in qualification testing will be available to support near-term production.

Facilities and equipment used for the production of CBCF are being upgraded. A stateof-the-art control and data logging system was implemented on the carbonization furnace. A new proportional-integral-derivative controller was installed on the vacuum molding station. Upgrading of the flow meter, flow control valve, and valve controller are planned for early FY 2010. The overall objective is to achieve better control of vacuum molding operations with electronic monitoring and recording of key parameters.

The high vacuum furnace used for outgassing $\mathrm{CBCF}$ qualification specimens has remained operational through continuous maintenance and calibrations. Since this furnace has been in service for more than thirty years, replacement is under consideration.

A new Flashline ${ }^{\mathrm{TM}}$ Thermal Diffusivity Measuring System used for the determination of thermal conductivity of $\mathrm{CBCF}$ was acquired by the High Temperature Materials Laboratory. The system should be made fully operational in the first quarter of FY 2010. CBCF production from FY 2008-2009 still await thermal conductivity determination for final qualification. Final qualification of Durez 22352 Resin Lot 18 FF6095 received in April 2008 requires thermal conductivity measurements.

Spark Source Mass Spectrometry analysis of CBCF samples was performed by Northern Analytical Laboratory of Merrimack, New Hampshire. Preliminary results indicate that Northern Analytical could serve as an alternative provider of this service for the determination of impurities in CBCF. More work will be required to establish a test procedure and confirm that reproducible results can be obtained.

\subsection{IRIDIUM ALLOY BLANK AND FOIL PRODUCTION}

The goals for this activity are to produce flight-quality (FQ) iridium alloy blanks used for fuel clad cup forming and iridium alloy foil which is used for other clad vents set components. The clad vent sets (CVS) are made under full configuration control, maintain production capability, and to supply materials needed for CVS production and maintenance activities. During FY 2009 a total of 10 blanks from ingot from K3 ingot were produced and stored with an approved data package. An upgraded control system for the vacuum arc remelting (VAR) furnace was qualified for production.

\subsubsection{Blank Production}

Melting and extrusion of the K3 ingot was performed during FY 2005. Rolling of the material to sheet was completed in FY 2006. Five of the 17 sheets were processed in FY 
2008 to produce 30 blanks. An additional two sheets were processed in FY 2009 to produce blanks. A total of 12 blanks were electro discharge machined (EDM) from sheets K3-6 and K3-7 and surface ground. All of the blanks passed dimensional, ultrasonic, dye penetrant and visual inspection inspections. The blanks were sampled and cleaned. The results of chemical and metallographic analysis were acceptable and in the normal range. A data package was prepared for the 12 blanks. The blanks were placed in storage with the approved data package in July 2009. No nonconformance reports (NCR) were issued during FY 2009.

\subsubsection{Qualification of Upgraded Control System for Vacuum Arc Remelting Furnace for Melting of Iridium Alloys}

\subsubsection{Background}

The 8-inch Consarc VAR Furnace was installed in 1990. The furnace is used to melt iridium alloy ingots for the iridium alloy blank production. The melt control system was replaced in FY 2007 with a sixth-generation PLC system in order to avoid long-term issues of component obsolescence. The new control system included an Allen Bradley PLC5-40 controller, additional analog I/O modules, a new computer with the Windows XP operating system and a software interface written in Visual Basic. It also included a new flat panel monitor, printer, UPS, load cell digitizer, and a paperless chart recorder capable of storing data at $125 \mathrm{~ms}$ intervals ( 8 per second). The melt stirring power supply control was integrated into the melt controls using the stored programs or melt profiles.

Training of two technicians in the operation of the furnace was conducted during the period of June-July 2009. During the month of August 2009 the reliability of the new control system was demonstrated by the melting of eight stainless steel (Type 304) ingots. These melts were all performed with the established steady-state control parameters for stainless steel of $1700 \mathrm{~A}$ and $26.5 \mathrm{VDC}$. The control parameters during the ramp up at the beginning of the melt and "hot top" at the end of the melt were varied in order to optimize the arc initiation and ingot yield.

\subsubsection{Procedure}

On the basis of the experience with the melting of the stainless steel, a draft revision of the equipment operating guideline (MET-MatP-SOP-120, "Consarc 8-in., VAR Laboratory Furnace"), and a draft revision of the iridium alloy melting procedure (METMatP-SOP-99, "Arc Melting of Iridium Alloy Consumable Electrodes") were prepared. The revisions are mostly to reflect the changes in the instructions for operation of the equipment using the new computer control system and for the use of new recording devices. Melt data is now recorded electronically, viewed on displays during the melt, and retained as hard copies that are printed after melting.

An electrode was prepared from iridium alloy scrap material. The electrode identified as RS17, with a weight of $13.2 \mathrm{~kg}$, consisted of both extruded scrap and melted and dropcast scrap assembled by electron beam (EB) welding. The scrap material does not have 
traceability needed for prime material and in some cases may have impurity elements Mo and $\mathrm{Nb}$ slightly above the specification limits for iridium alloy blanks.

A melt profile for the RS17 electrode containing all control parameters for the melt was prepared using identical control parameters of $3000 \mathrm{~A}$ and 31 VDC as used for previous production melts during the steady state portion of the melt. The control parameters for the start and end of the melt were selected on the basis of both previous melts of iridium and the recent experience from the melting of stainless steel.

The furnace was cleaned, the crucible was prepared, and the electrode loaded into the furnace following the draft procedure. The melt was initiated and controlled by the computer during the entire melt cycle. The melt operation as monitored by charting of vacuum level, electrode position, arc current, and arc voltage. In addition visual observation of the melt was performed both directly through a furnace site port and by video cameras. No unusual behaviors were seen that would have been reason for early termination of the melt.

\subsubsection{Results}

A photograph of the melted RS17 ingot surface in Fig. 1 shows a smooth surface and no indications of discoloration. The electrode stub in Fig. 2 shows a normal appearance and a relatively flat end. The crucible showed no damage from arc shorts and the ingot was removed without the need for any applied pressure.

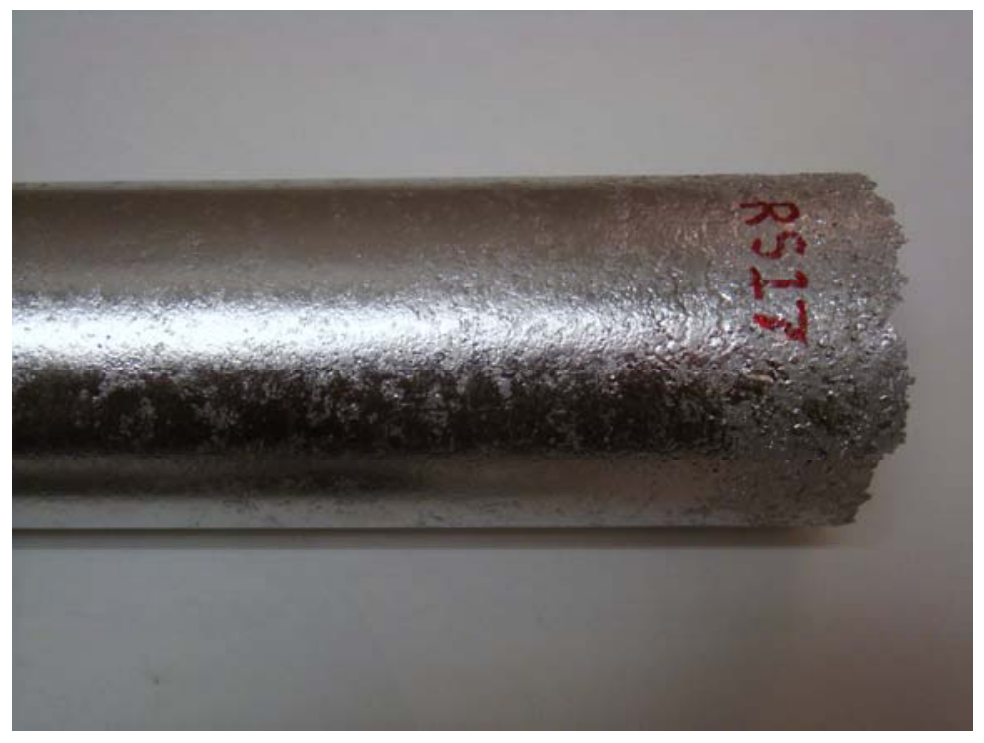

Figure 1. Surface of RS17 iridium alloy scrap ingot.

The chart recording of the melt parameters is shown in Figure 3 . The current and voltages were maintained at the nominal control point values of $3000 \mathrm{~A}$ and $31 \mathrm{VDC}$ during the steady state portion of the melt. The current ramped from $1800 \mathrm{~A}$ at the initiation of the melt to the steady state value in $25 \mathrm{~s}$. The hot top portion ramped from $3000 \mathrm{~A}$ to $1800 \mathrm{~A}$ in $40 \mathrm{~s}$. Vacuum levels were in a normal range and electrode feed was 


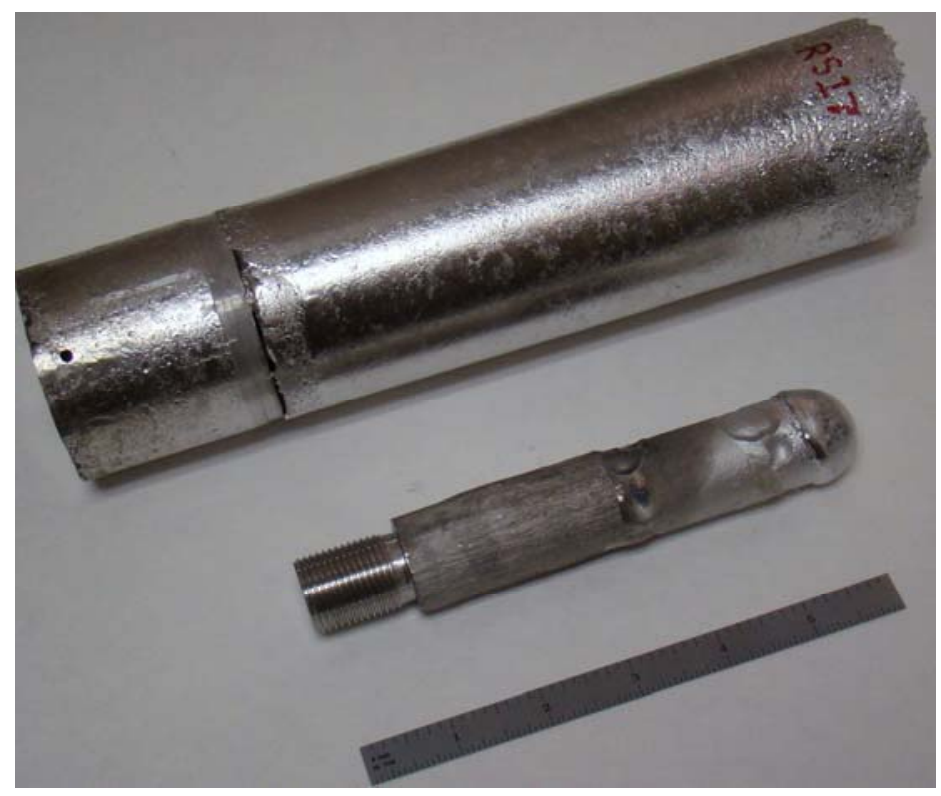

Figure 2. RS17 iridium alloy scrap ingot and electrode stub.

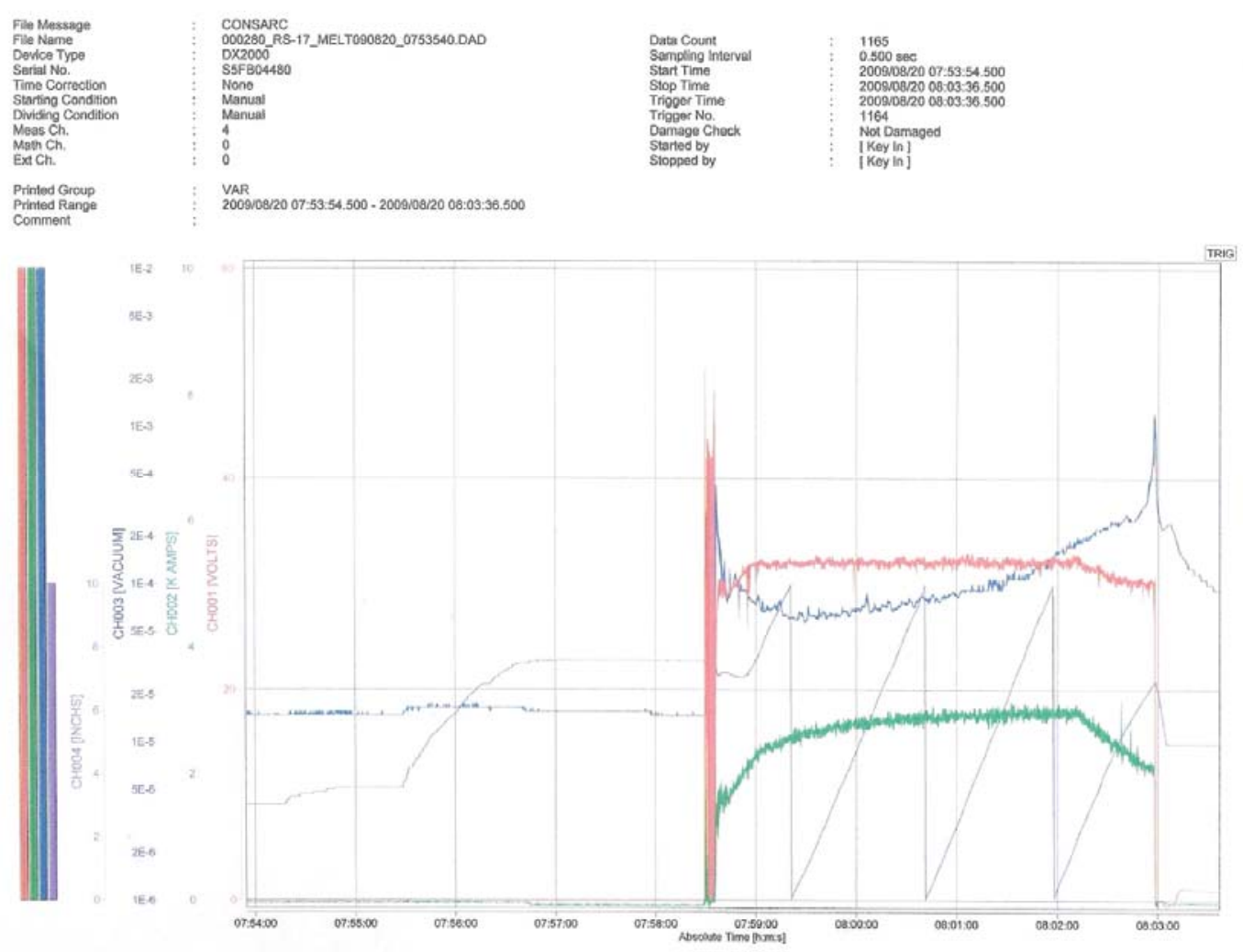

Figure 3. Chart recording of melting conditions of iridium scrap ingot RS17 shows initial leak rate test of the furnace followed by melting of the ingot. The arc current in amps (green) ramps to $3000 \mathrm{amps}$ and is later ramped to $1800 \mathrm{amps}$. Arc voltage (red), vacuum (blue), and position (purple) are also shown. 
uniform. Similar data is shown in Figure 4, in the graph obtained from the computer control and data acquisition (DAQ) system, including the voltage set point in addition the measured voltage. The small oscillations of both current and voltage about the control set point values is associated with drips of liquid passing through the arc gap and is an indicator of an arc gap distance in the desired range.

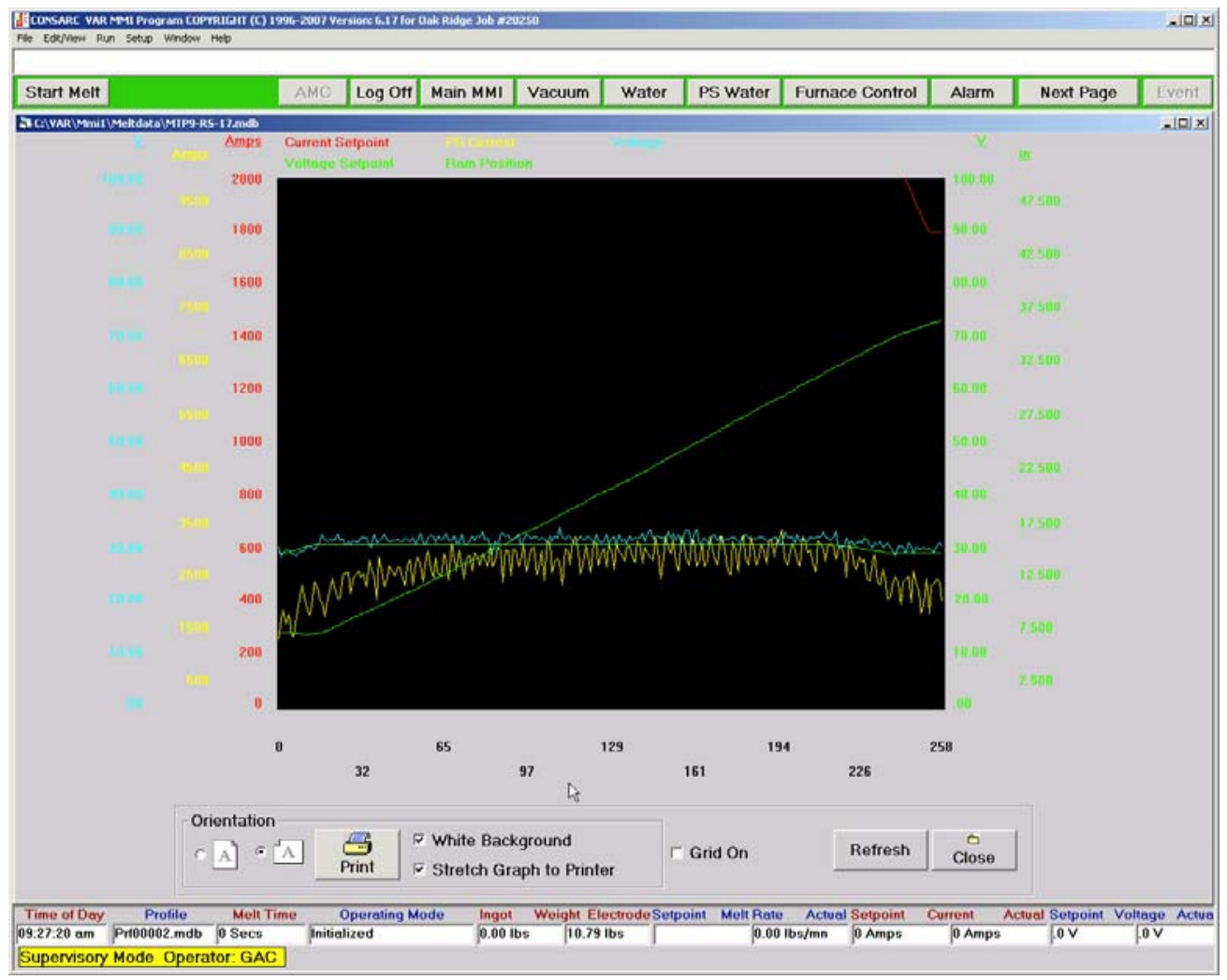

Figure 4. Plot from computer control system of melting conditions of iridium scrap ingot RS17 shows arc current in amps (yellow), arc voltage and arc voltage set point (blue), and position (green).

\subsubsection{Conclusions}

1. The new control system on the VAR furnace has shown consistent operational behavior through a campaign of eight melts of stainless steel over a period of four weeks.

2. The iridium alloy scrap ingot, RS17, was successfully melted with the new control system using a draft revision of the procedure for melting of iridium materials.

3. The melting of RS17 ingot proceeded normally as evidenced by visual observations during the melt, chart recordings of melting parameters over the duration of the melt, and the visual appearance of the ingot, electrode stub, and copper crucible following the melt. 
4. The new control system of the VAR furnace is qualified for melting iridium alloy electrodes for blank production.

5. A deviation request will be issued to revise procedure MET-MatP-SOP-99, "Arc Melting of Iridium Alloy Consumable Electrodes," to accommodate detailed instructions for use of the new control system. No changes will be made in steady state melt parameters.

\subsubsection{Training}

One technician was trained in the procedure for button arc melting of iridium. A second technician was retrained in this operation after returning to the group following a threeyear absence. In both cases the training included the arc melting and drop-casting of iridium scrap materials. This technician was retrained in the acid cleaning of metals. The technician was also trained in the in operation of the Consarc Vacuum Arc Remelt (VAR) furnace, precious metal accounting, and the procedure for shipping of iridium alloy blanks and foil. The technician has been assigned the responsibility of balance point custodian for RPS materials in this task. Training of the technician was initiated in the operation of the vacuum annealing furnace.

\subsubsection{Chemical Analysis}

\subsubsection{Qualification of Alternate Source for Oxygen Analysis by Inert Gas Fusion}

Analysis of iridium alloy materials has been performed at Oak Ridge B\&W Y-12 National Security Complex for the past fifteen years and is currently performed using a Leco TC-436 Oxygen/Nitrogen Analyzer. During FY 2009 Leco Corp was qualified as an alternate source to Y-12 to assure timely availability of analytical results. Leco Corp. is the largest manufacturer of this type of analytical equipment in the US and is ISO 90001:2000 registered by BSI Management Systems (Americas) a branch of the British Standards Institute for the marketing, design, manufacture and service of analytical and metallographic instruments, and consumable operating supplies, as well as laboratory services and domestic and international order systems. Leco was previously qualified for carbon analysis of iridium materials by combustion (see RPS program annual report for FY 2008.) A standard operating guideline was developed for the analysis of iridium materials at Leco using the Leco TC600 series oxygen determinator.

A study was conducted to compare results obtained from Leco and Y-12 for reference materials of both iridium alloy solids and iridium powder. The solid iridium alloy reference materials were prepared from cups, sheet, and foil. Multiple specimens were prepared from each of six iridium alloy cups that had been designated as d-test samples. In cases where this provided insufficient material, supplementary archive materials from the same sheet were used. All samples were identified by sheet number. A portion of iridium alloy sheet, identified as RS12, was used to prepare a reference material representative of iridium alloy blanks. The sheet was sectioned to pieces of about 0.1 gram each, which were cleaned and then blended to provide a homogeneous material from which samples were obtained. A similar process was used to prepare a sample of 
foil material identified as MS3-2. All samples were cleaned in accordance with the current procedures for preparation of samples for oxygen analysis. Thus a total of eight reference materials were prepared for analysis of iridium alloy solids. A total of six lots of iridium powder were individually blended to produce homogeneous reference material samples.

Each reference material was analyzed at Y-12 at two different times, separated by at least one week. Each of the results was the average of at least two aliquots, or individual runs of the sample provided. Each reference material was also analyzed at Leco at two different times, separated by at least one week, with the exception of the foil samples that were analyzed in sequence. Each of these results was the average of three aliquots, or individual runs of the sample provided. The results for iridium alloy solids are listed in Table 1 and the results for iridium powder are listed in Table 2.

Table 1. Comparison of Average Oxygen Analyses (ppm) by Y-12 and Leco for Solid Reference Materials

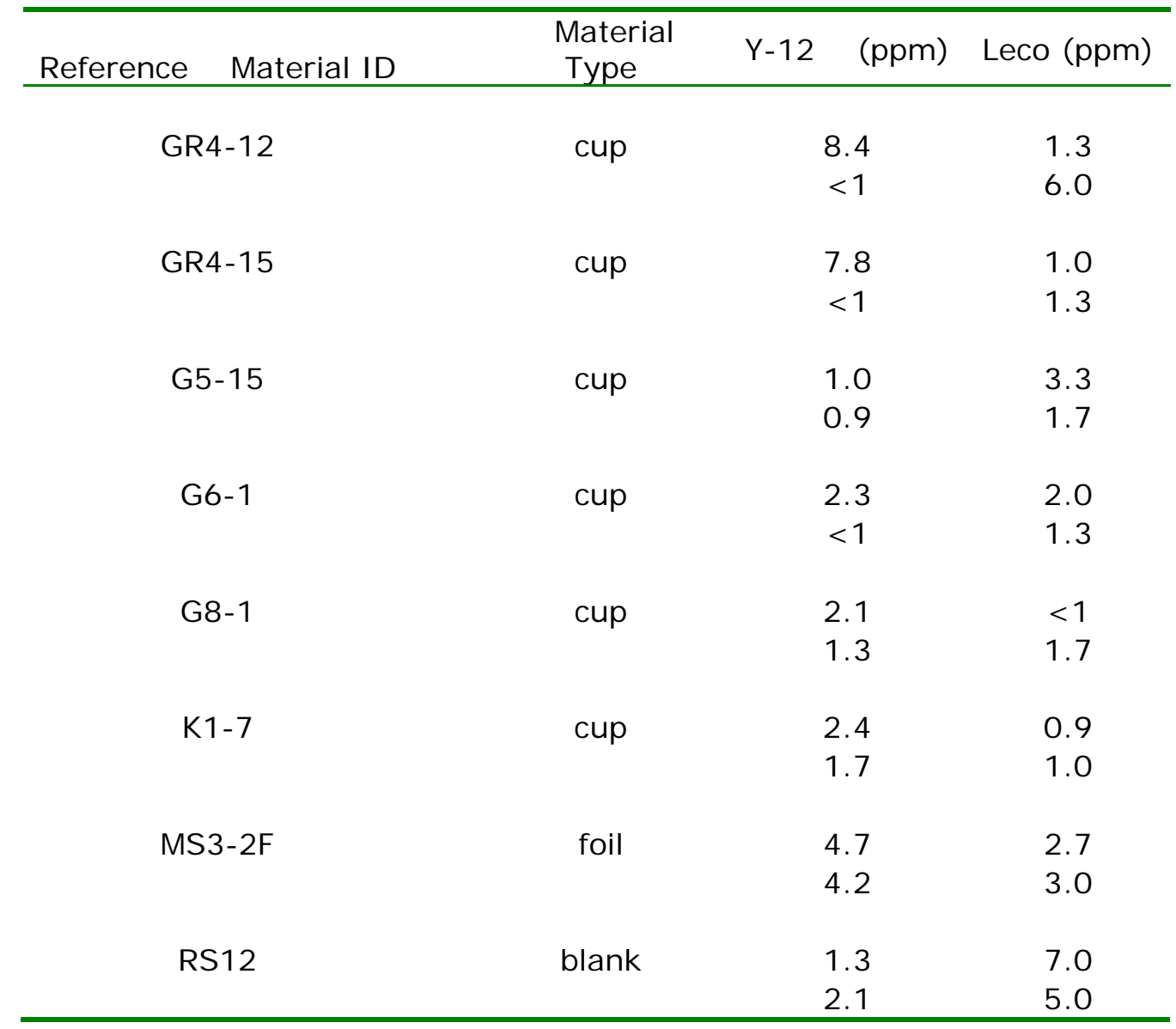

Note: Results are reported to the nearest $0.1 \mathrm{ppm}$. The average values do not imply accuracy greater than $1 \mathrm{ppm}$ but are used for statistical analyses. 
Table 2. Comparison of Average Oxygen Analyses (ppm)

by Y-12 and Leco for Powder Reference Materials

\begin{tabular}{lcc}
\hline $\begin{array}{r}\text { Reference } \\
\text { Material ID }\end{array}$ & Y-12 $(\mathrm{ppm})$ & Leco $(\mathrm{ppm})$ \\
\hline \multirow{2}{*}{ OIR 032/01A/5 } & 422 & 353 \\
& 427 & 350 \\
$\mathrm{JM} / 6 / 1 \mathrm{~A}$ & 296 & 284 \\
& 293 & 276 \\
$\mathrm{JM} / 6 / 1 \mathrm{~B}$ & 293 & 283 \\
& 308 & 283 \\
& & 278 \\
$\mathrm{JM} / 91-0087 / 4 \mathrm{~B}$ & & \\
& 271 & 280 \\
JM/92-0032/5 & 269 & 259 \\
& 412 & 402 \\
$\mathrm{R} / 12800 / 21 / \mathrm{B}$ & 411 & 391 \\
& & 329 \\
& 337 & 325 \\
\hline
\end{tabular}

A statistical analysis of results was performed. Any value less than $1 \mathrm{ppm}$ was assigned a value of $0.5 \mathrm{ppm}$ for the purpose of this analysis. The average of the Leco value minus the Y-12 value is $0.07 \mathrm{ppm}$ for solids and $-22 \mathrm{ppm}$ for powders. Neither of these differences is statistically different from zero at a $95 \%$ level of confidence. For both solids and powders the pooled standard deviations for Leco and Y-12 are not statistically different from each other at a $95 \%$ level of confidence. There is no statistical bias between Leco and Y-12.

In the case of solids (cups, blanks, or foil) a reported result by Leco can be expected to agree with a Y-12 reported result within $\pm 8 \mathrm{ppm}$ at a $95 \%$ level of confidence. For solids the repeatability for analysis by Leco is \pm 3 ppm at a $95 \%$ level of confidence vs. \pm $6 \mathrm{ppm}$ for Y-12.

In the case of powder, a reported result by Leco can be expected to agree with a Y-12 reported result within $\pm 22 \mathrm{ppm}$ at a $95 \%$ level of confidence. The repeatability for the Y12 analysis of powders is $\pm 12 \mathrm{ppm}$ at a $95 \%$ level of confidence. The repeatability for the Leco analysis of powders is $\pm 16 \mathrm{ppm}$ at a $95 \%$ level of confidence. This is considered acceptable especially because oxygen analysis on powder samples is for information only.

Leco Corp, Saint Joseph, MI, was qualified for oxygen analysis of all iridium materials in accordance with an approved guideline. 


\subsubsection{Glow Discharge Mass Spectrometry}

An improved design for a new iridium sample holder for glow discharge mass spectrographic analysis was completed in consultation with the technical expert at the analytical service provider. A drawing of the holder was reviewed by the QA representative and fabricated from iridium alloy scrap material. The purpose of the new design is to address potential issues with variations in sample heating and electrical contact resistance during the analysis, with the aim of improved repeatability in the analytical results. Trend analysis will be conducted as additional analytical results are obtained.

\subsubsection{Deviation Requests}

The following deviation requests were approved in FY 2009:

DR-Ir-226 revised Procedure MET-MatP-SOP-90 "Preparation of Master Alloys for Iridium Doping.," to show new button melting furnaces previous approved for iridium melting and change in storage location for thorium alloying material.

DR-Ir-230 introduced Guideline MET-MatP-SOG-111,"Oxygen analysis of iridium and iridium alloys by inert Gas Fusion" for oxygen analysis of samples of blanks, foil, cups, and powder by an outside service provider.

\subsubsection{Equipment Major Maintenance and Purchases}

A specification was approved for the purchase of new vacuum control and emission control systems for the EB Melting Furnace. A purchase order is expected early in FY 2010, with installation and final acceptance testing expected to complete by September 2010. This equipment upgrade is being purchased with FY 2009 capital funds.

A purchase order was placed for a replacement water-cooling system for the EB melting furnace. The new system replaces a 20 year old system that could no longer be repaired. Removal of the obsolete cooling water system was completed. Delivery of the new system is scheduled for November 2009. This equipment was purchased with FY 2009 capital funds.

Three vacuum pumps from the EB melting furnace were rebuilt and reinstalled in May following nearly twenty years of service. 


\subsubsection{Publications and Presentations}

\subsubsection{Publications}

Ohriner, E. K., Sabau, A., Ulrich, G. B, George. E. P., Deformation Modeling of Iridium DOP-26 Alloy to Determine Potential for Secondary Recrystallization, in 2008 International Conference on Tungsten, Refractory \& Hardmaterials VII, Metals Powder Industry Federation, Princeton, NJ, pp. 9-55 to 9-66.

\subsubsection{Presentations}

Abstract accepted for presentation at TMS 2010 Annual Meeting, Feb 14-18, 2010, Seattle WA:

E. K. Ohriner, G. B. Ulrich, R. G. Miller, and W. Zhang, "Surface processing of an iridium alloy."

\subsection{CLAD VENT SET}

\subsubsection{Maintenance Production Summary}

Three prime quality CVS were produced in 2009 as part of the DOE CVS Production Maintenance program. CVS production facility operability was maintained throughout the year. Training of personnel was maintained for all CVS operations during FY 2009. Trend analyses were maintained for all part types. No adverse trends were noted at the end of the year. Five of the six CVS surveillances, per the Surveillance and Process Monitoring Plan for the RPS Program CVS and CBCF Production Tasks, GPHS-QA002, Revision G (Appendix B), were successfully completed during the year. The CVS surveillances are listed below.

\section{Welding Equipment (Laser and EB) \\ Reinspection \\ Tooling Identification and Control \\ Measuring and Test Equipment \\ Instructions, Procedures, and Drawings \\ Personnel Training}

The surveillance entitled "Instructions, Procedures, and Drawings" (S-MC-CVS-009006) examined the labeling for eight Engineering Use matched assemblies, 9808-31-6340 through 6347, that were prepared in FY 2009. These units were stored as required with red labels and the proper part identities, however, the reasons for the NCRs were not recorded on the labels as required by MET-SA-PMP-6 and the applicable processing procedures. Procedures GPHS-G-9753 and GPHS-G-9754 were revised and two deviation requests DR-CVS-080 and DR-CVS-081 were prepared to address the surveillance deficiencies. Also MET-SA-PMP-6 was revised. A follow-up surveillance, 
S-MC-CVS-009-007, found that the original labeling deficiencies were corrected with the reasons for the NCRs/NCR numbers on the red labels.

\subsubsection{Nonconformance Reports}

Two NCRs, NCR-CVS-073R1 and -074, were submitted and accepted in FY 2009. NCR-CVS-073R1 was for vent cup assemblies (VCA) 9753-05-4364 through 4374. The frit vent assembly-to-vent cup tack welds were made with Alignment Tools per Drawing, N3C021194A001, Rev. 0, Item 2 (FVA Alignment Tool). The drawing had not been revised to reflect the as-built dimensions for three (serial numbers 2,4 , and 5) of the five FVA Alignment Tools when DR-CVS-074 was submitted (9/25/08) and approved (11/5/08). Five FVA Alignment Tools and five DC Alignment tools had been machined using an approved sketch (as-designed). After receipt, the Alignment Tools were dimensionally inspected with three of the five FVA Alignment Tools not meeting the asdesigned sketch. The DC Alignment Tools were acceptable. Testing with setup and weld qualification hardware showed that the three nonconforming FVA Alignment Tools did not affect the alignment of FVAs or the tack welding. The as-designed tooling drawing should have been revised to incorporate the acceptable as-built dimensions along with the procedure changes through the deviation request process. However, deviation request DR-CVS-074 was approved without incorporation of the as-built tooling dimensions. Production welding of eleven VCA followed. In preparation for the quality review of the completed VCA it was discovered on December 15, 2008 that the Alignment Tool drawing contained the as-designed dimensions and not the as-built dimensions. Based on the manner in which they were processed, between five and nine vent cups used Alignment Tools not meeting the approved as-designed drawing. All of the VCA were accepted for Use As-Is based on successful subassembly inspections.

NCR-CVS-074 downgraded VCA 9753-05-4375 through 4377 to EUO for potential analytical evaluation or other ORNL-discretionary non-prime use. These 3 VCA were welded during the same welding pumpdown cycle. Visual examination by the welding operator after completion of the frit vent-to-cup welds revealed that VCA 9753-05-4376 had cracking on the outside bottom of the cup (backside of the frit vent-to-cup weld) and it appeared to have a weld "burn-through" area. VCA 9753-05-4377 had a large $(\sim 1 \mathrm{~mm}$ diameter) black spot/stain area on the outside bottom of the cup at the grit blast/non-grit blast area interface along with some other smaller areas on the outside bottom of the cup. VCA 9753-05-4375 had a few small black spot areas on the outside bottom and the inside bottom of the cup.

Scanning electron microscope and energy dispersive x-ray spectroscopy (SEM/EDS) evaluations of these black spot areas on the VCAs and particulates in the EB weld chamber and on the Ten Head Weld Positioner (T2E-140445) tooling showed that all were mostly rich in aluminum. These evaluations indicated that the chamber and the tooling were inadequately cleaned prior to the frit vent-to-cup weld operation and this allowed 6061 aluminum alloy particulates abraded from the tooling to be circulated in the weld chamber during the pumpdown and backfill cycles. 
Certain features of the Ten Head Weld Positioner tooling are being re-designed to minimize the generation of particulates, especially aluminum, in the EB chamber. All welding personnel will be re-trained to ensure proper tooling and chamber cleanliness for welding. Characterization of the interaction between the 6061 aluminum particles and the iridium alloy material will continue in FY 2010.

\subsubsection{Deviation Requests}

Five DRs, DR-CVS-076 through 079 plus DR-Ir-230, were processed in FY 2009. DRCVS-076 addressed revisions to the WS Butt Welding Procedure, GPHS-K-3620 (to Rev. 4). These revisions involved corrections/updates to the tooling/equipment/materials listing and modification of the welding parameters based on re-qualification work required after the EB welder control system upgrade last year.

DR-CVS-077 addressed revision of Frit Vent and Decontamination Cover to Vent Cup Welding Procedure GPHS-K-9753 to Rev. 5. This incorporated corrections to the Alignment Tool Drawing, N3C021194A001, Rev. 1, as noted in the discussion of NCRCVS-073R1.

DR-CVS-078 addressed changing the Frit Vent Laser Welding Procedure GPHS-K-9752, to Rev. 13. Beside the editorial/format revisions, many of the changes involved making this procedure consistent with changes made to other procedures over the last few years. Also clarifications and corrections were made to the laser welding parameters and the $\mathrm{CNC}$ welding program.

DR-CVS-079 concerned changing the Cup Destructive Test Sample Preparation Procedure GPHS-XF-3624/25A, to Rev. 11. Editorial/format revisions were made along with tooling drawing changes, simplification of cup segment scribing, combining of two cup segment pieces for oxygen testing of 3 aliquots per MST-MatP-SOG-111, and simplification of the sample identification system.

DR-Ir-230 for the new Oxygen Analysis of Iridium and Iridium Alloys by Inert Gas Fusion Guideline MST-MatP-SOG-111, Rev. 0, allows the LECO Corporation to serve as an analytical back-up source for oxygen in iridium testing. Extensive analytical testing was conducted at Y-12 and LECO using powder, foil, sheet, and cup samples over two time periods referred to as "Week 1" and "Week 2". Statistical analyses of the results showed that LECO is qualified for this analysis.

\subsubsection{Qualification of Mahr Federal MarForm MMQ 400 Form Measuring Instrument for CVS Cup Roundness and Flatness Inspections - Milestone 2.C.4}

Roundness (or circularity) and flatness measurements are made as part of the dimensional inspection process to certify that CVS cups meet the dimensional requirements of Iridium Alloy Cup Drawing M2D920101A005, Rev. 4. A Federal Products Corporation (Providence, RI) Formscan 3200 Circular Geometry Gage is specified in the cup inspection Procedure GPHS-C-3624/25, Rev. 23 for roundness (dimension 16) and 
flatness (dimension 17). The Formscan 3200, built in 1990, utilizes a MS-DOS 3.3 operating system. A new Mahr Federal (Providence, RI) MarForm MMQ 400 Formtester with a MS Windows XP operating system was purchased in 2008 by the ORNL Metrology Laboratory to replace the Formscan 3200.

Evaluations were conducted to qualify the new MMQ 400 for CVS cup dimensional inspection work. The criterion for qualification was to ensure that the new MMQ 400 instrument would yield roundness and flatness inspection results comparable to the existing Formscan 3200 instrument. Evaluations have shown that the new MMQ 400 yields CVS cup roundness and flatness inspection results that are comparable to the existing Formscan 3200 instrument. These evaluations are documented in the ORNL Letter Report 1014-27-09 dated 10/14/09 and entitled "Contract No. DE-AC0500OR22725, Qualification of Mahr Federal MarForm MMQ 400 Form Measuring Instrument for CVS Cup Roundness and Flatness Inspections”.

The new MMQ 400 instrument was considered fully qualified for CVS cup dimensional inspection work per procedure GPHS-C-3624/25 after the annual calibration check was completed successfully in early October 2009. A deviation request will be submitted for revision of procedure GPHS-C-3624/25 to incorporate use of the MMQ 400 instrument in place of the Formscan 3200.

\subsubsection{Decontamination Cover Tooling}

A study was begun in FY 2008 to evaluate the potential for improving the decontamination cover blank flattening operation before forming. Flatter decontamination cover edges can aid the EB weld operation. The study was halted because of mixed dimensional inspection results for decontamination cover diameters measured using a micrometer, an Olympus STM comparator/toolmaker's microscope, and a Mitutoyo QVAce 200 vision measuring machine (VMM). Now with incorporation of tack welding prior to the full circumferential decontamination cover-to-cup weld there is less need for flatter decontamination cover edges. Nevertheless, there is still a need for a fast reliable inspection technique for evaluating parts made from new tooling or after tooling changes. Micrometer measurements are very tedious while the STM measurements are almost as tedious. The VMM is a very fast and repeatable measuring instrument. If the correct inspection parameters can be found for the VMM it will be very beneficial for these evaluations.

In FY 2009 a study was begun to optimize the VMM for measuring the outside diameter of decontamination covers using the two Reinspection Surveillance decontamination covers, 3619-01-005 and -015. The goal is to match the results as closely as possible to those from the Olympus STM used for production dimensional inspection. The Reinspection data from the last 11 years is being used for this matching. VMM inspections were done for each part 10 times and then each part was removed/rotated two more times with 10 inspections after each remove/rotate iteration. The VMM box tool was used in 3 places to find/align the part. Inspections were completed using $1 \mathrm{X}$ and 10X magnifications and stage lighting settings of 7, 10, and 15 with six inspection points. Also six-point VMM inspections were completed using $2 \mathrm{X}$ magnification (1X objective 
and $2 \mathrm{X}$ tube lenses) with stage lighting settings of 7 and 10 plus $6 \mathrm{X}$ magnification (1X objective and 6X tube lenses) with stage lighting setting of 23. So far VMM inspection results using $1 \mathrm{X}$ magnification and stage lighting setting of 7 have produced the best match with the reinspection data from the Olympus STM.

In FY 2010 a VMM inspection will be done using 1X magnification and stage lighting of 8 with six inspection points followed by an inspection using the same parameters except with 12 inspection points. The final planned VMM inspection will involve $5 \mathrm{X}$ magnification (5X objective and $1 \mathrm{X}$ tube lens) with the lowest possible light setting and 12 inspection points.

\subsubsection{Cup Sizing Evaluations}

The current cup production sizing operation is performed at room temperature after the recrystallization operation. The outer surface of a cup is lubricated prior to placing it in a closed steel die. Hydrostatic pressure is applied through a polyurethane punch nose on the inside of the cup to size the cup to the proper final diameter, radius, and roundness dimensions. Cup sizing evaluations in FY 2008 showed that when sizing before recrystallization the wrought (as-formed) cups do not possess enough ductility to achieve proper dimensions. It was decided to continue the sizing load evaluations using recrystallized cups and new sizing punches to determine the practical minimum and maximum sizing load limits. In FY 2009 duplicate sizing punches were fabricated from polyurethane stock with Durometer readings of 80, 90, and $95 \mathrm{~A}$. They have been dimensionally inspected. In FY 2010 recrystallized cups will be sized and inspected to evaluate the effect of the punches and/or sizing loads on cup dimensions.

\subsubsection{Frit Vent Tooling Evaluation}

During FY 2008 graphite sintering tooling materials POCO Graphite [Decatur, TX] grade DFP-1 and Graphtek LLC [Buffalo Grove, IL] grade GM-10 were evaluated to address the problem of iridium powder sticking to the graphite tooling instead of the frit vent backing disc during sintering. The intent was to find a material machined to the required surface finish of $16 \mu$ in $R_{a}$ that would perform better (lower incidence of iridium powder sticking to the graphite pins and/or bushings during sintering) than the currently-specified UCAR (Clarksburg, WV) ATJ graphite. Unfortunately, dimensional and visual (10X to $20 \mathrm{X}$ ) inspections of the new sintering tooling components showed the tooling surfaces to be rougher than desired.

During FY 2009 six ATJ graphite sintering tooling Pins were sent to CiDRA Precision Services, LLC (Wallingford, CT)) to evaluate their ability to properly lap the ends to meet the Pin end face surface roughness requirement of $16 \mu \mathrm{in} \mathrm{R}_{\mathrm{a}}$. The ends of the Pins were polished dry with diamond lapping papers (initially $3 \mu \mathrm{m}$ and then finished with 1 $\mu \mathrm{m})$ to a reported surface finish of $4 \mu \mathrm{in} \mathrm{R}_{\mathrm{a}}$. ORNL Dimensional Inspection measured the surface finishes to be $10-16 \mu$ in $\mathrm{R}_{\mathrm{a}}$.

Four series of frit vent assembly sintering $\left(1500^{\circ} \mathrm{C} \backslash 1 \mathrm{~h}\right)$ runs were made using six productions (unpolished) ATJ Pins and the six ATJ Pins with the end faces polished by 
CiDRA Precision Services. These runs were made using two powder lots - 21,012800, jar A and 92-0035, jar 6 and two operators. Prior to the first sintering run the furnace and all tooling were outgassed at $1900^{\circ} \mathrm{Cl} 2 \mathrm{~h}$.

After completion of the first sintering run, iridium powder (lot 21,012800, jar A) was found adhering to the Pin end faces for all six production Pins and five of the six polished Pins. Polished Pin \#5 was examined by scanning electron microscopy (SEM) to compare the half of the Pin end face where iridium powder adhered to the other half that had no iridium powder adhesion. The adhering powder was associated with rough surface pores/unsound-appearing ATJ graphite areas. The pores were typically $\leq 25 \mu \mathrm{m}$ while the associated residual iridium was typically $\leq 10 \mu \mathrm{m}$. Figures 5-7 show this after the bulk iridium powder was removed.

No iridium powder adhesion was encountered with any of the production or polished ATJ graphite sintering Pins for either run with lot 92-0035, jar 6 powder. Only one small area $(\sim 1 / 8$ of the sinter Pin face) of one production ATJ Pin had powder adhesion during the second run with powder lot 21,012800, jar A.

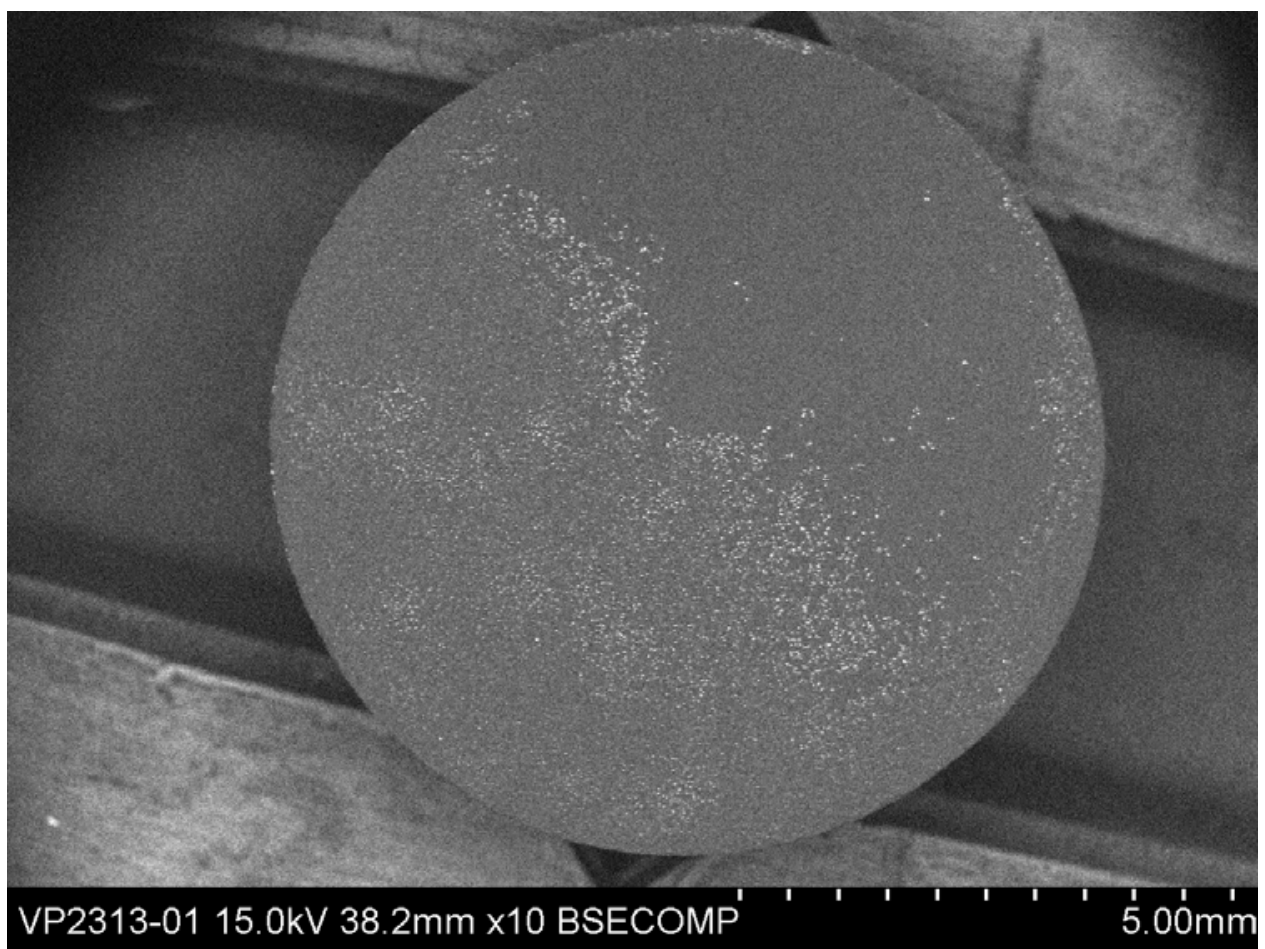

Figure 5. Backscattered electron image (10X mag.) of ATJ graphite Pin \#5 showing residual iridium powder from lot 21, 012800, Jar A adhering to over half of Pin face after removal of bulk powder. 


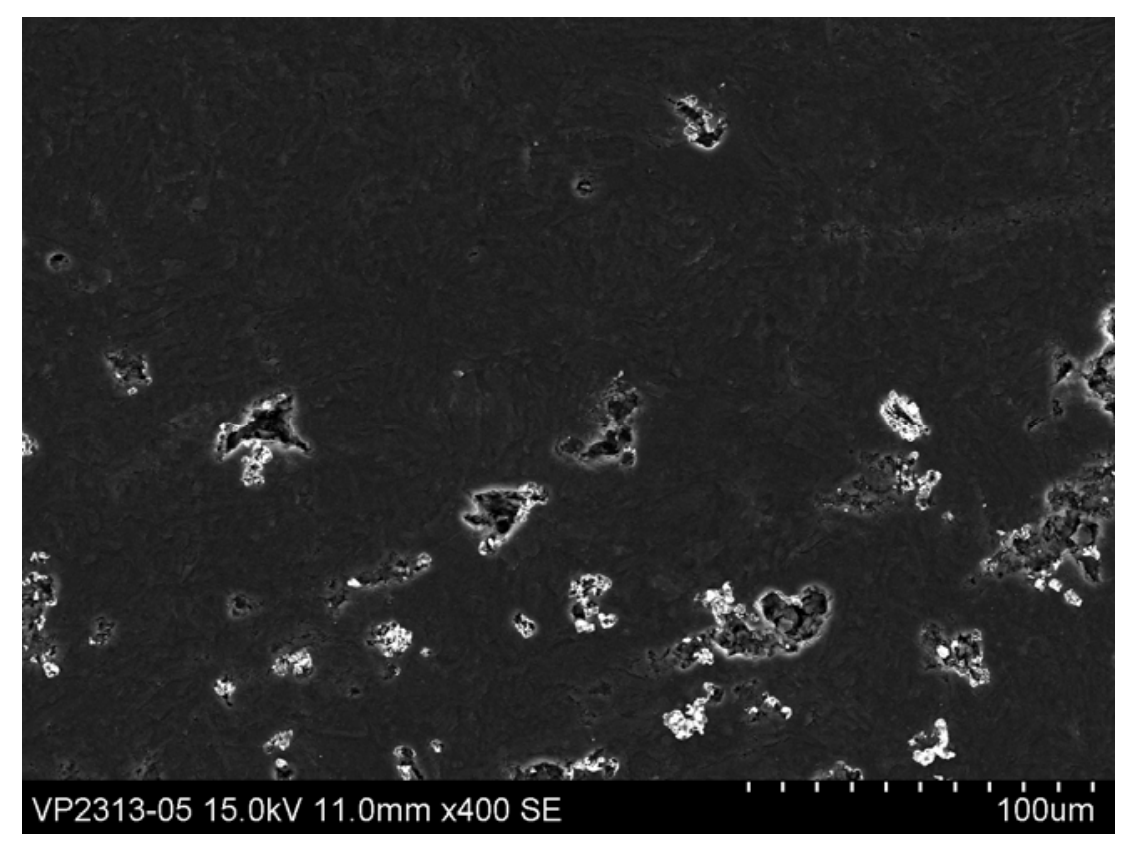

Figure 6. Secondary electron image (400X mag.) of ATJ graphite Pin \#5 showing residual iridium powder from lot 21, 012800, Jar A adhering to Pin face in porous regions after removal of bulk powder.

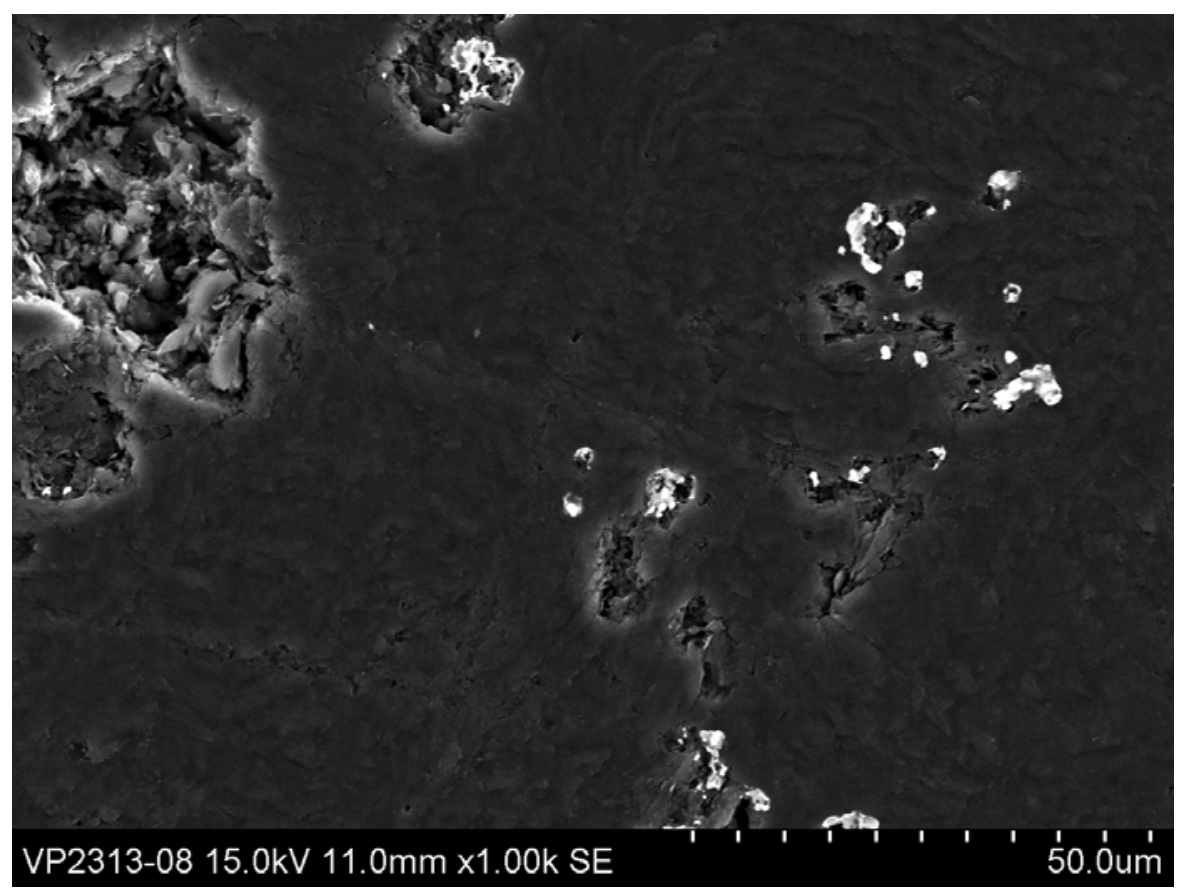

Figure 7. Secondary electron image (1000X magnification) of ATJ graphite Pin \#5 showing residual iridium powder from lot 21, 012800, Jar A adhering to Pin face in porous regions after removal of bulk powder. 
Time vs. temperature/vacuum profiles for the four sintering runs made using polished and unpolished ATJ graphite Pins were graphically compared. Nothing was found in the graphical profiles to explain the high incidence of adhesion for the first run versus the others. It was concluded that polishing of Pin end faces is not a solution to avoid powder adhering to ATJ graphite during sintering based on the results from these sintering runs with two sets of Pins, two powder lots, and two operators.

Next, 15 sets of Sintering Pins and Bushings were fabricated conventionally (no special polishing) from POCO AXF-5Q material ( $5 \mu \mathrm{m}$ particle size vs. $25 \mu \mathrm{m}$ for ATJ, a finer pore size and a coefficient of thermal expansion closer to that of iridium) for evaluation purposes. They were dimensionally inspected and then outgassed at $1900^{\circ} \mathrm{C} / 2 \mathrm{~h}$.

Four sintering runs were completed with ATJ and POCO AXF-5Q graphite Pins and Bushings using two iridium powder lots, 012800-Jar A and 92-0035-Jar 6. The first run had iridium powder (Lot 21,012800-Jar A) adhering to three out of six ATJ and two out of six POCO Pin faces. The second run had no iridium powder (Lot 92-0035-Jar 6) adhering to any of the ATJ Pin faces while adhesion occurred with two out of six POCO Pin faces. The third run, using different tooling sets than those used in the first two runs, had iridium powder (Lot 92-0035-Jar 6) adhering to one out of six ATJ and four out of six POCO Pin faces. A cursory SEM evaluation of the two POCO Pins with iridium powder adhesion from the first sintering run did not reveal an explanation for the adhesion (see Figures 8-12). The conventionally-fabricated POCO surfaces had higher integrity (less defects/finer pores) than the ATJ surfaces previously examined. A fourth sintering run was completed using the same tooling sets as the third run, but with iridium powder from lot 21,012800-Jar A. No powder adhered to any of the graphite Pins. The sum of these results showed that changing the sintering tooling material from ATJ to POCO graphite would not solve the problem of powder adhering to Pin tooling faces.

Two re-designs of the sintering tooling are being considered. The intent of any re-design would be to eliminate contact with the upper iridium powder surfaces and still shield the powder from any disturbances during the vacuum pumpdown. The first re-design involves elimination of the Pins by resting a second Spacer with longer graphite dowels on top of the six Bushings. The second re-design uses modified diffusion bond tooling Pressure Pins ( 0.4 inch long and 0.315 inch diameter below the existing 0.62 inch diameter hemispherical cap) in place of the standard sinter Pins. A set of six FVA were made with each re-designed sinter tooling set using iridium powder from Lot 92,0035Jar 6. Diffusion bonding and the flow test/compress steps were completed for the parts from both sinter runs. All FVAs yielded good flow rates and thicknesses. One FVA from each run was manually pulled apart to qualitatively evaluate the bonding. Both parts were well bonded.

Additional FVAs will be made in FY 2010 to evaluate these designs further. Note: the diffusion bond tooling Pressure Pins have been modified further $(0.25$ inch long and 0.315 inch diameter below a 0.50 inch diameter hemispherical cap with an overall Pin length of $0.50 \mathrm{inch}$ ) for the next evaluation runs. 


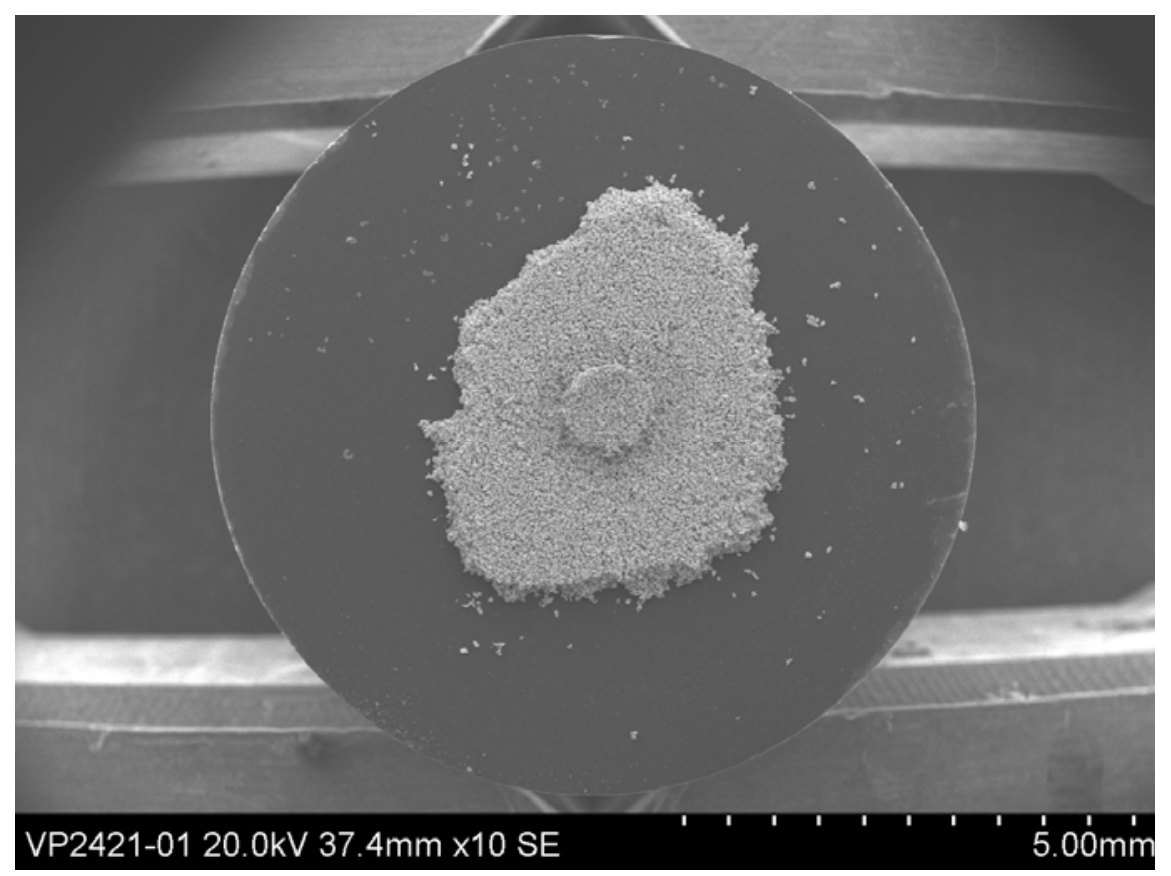

Figure 8. Secondary electron image (10X magnification) of POCO AXF-5Q graphite Pin \#3 showing residual iridium powder from lot 21, 012800, Jar A adhering to Pin face.

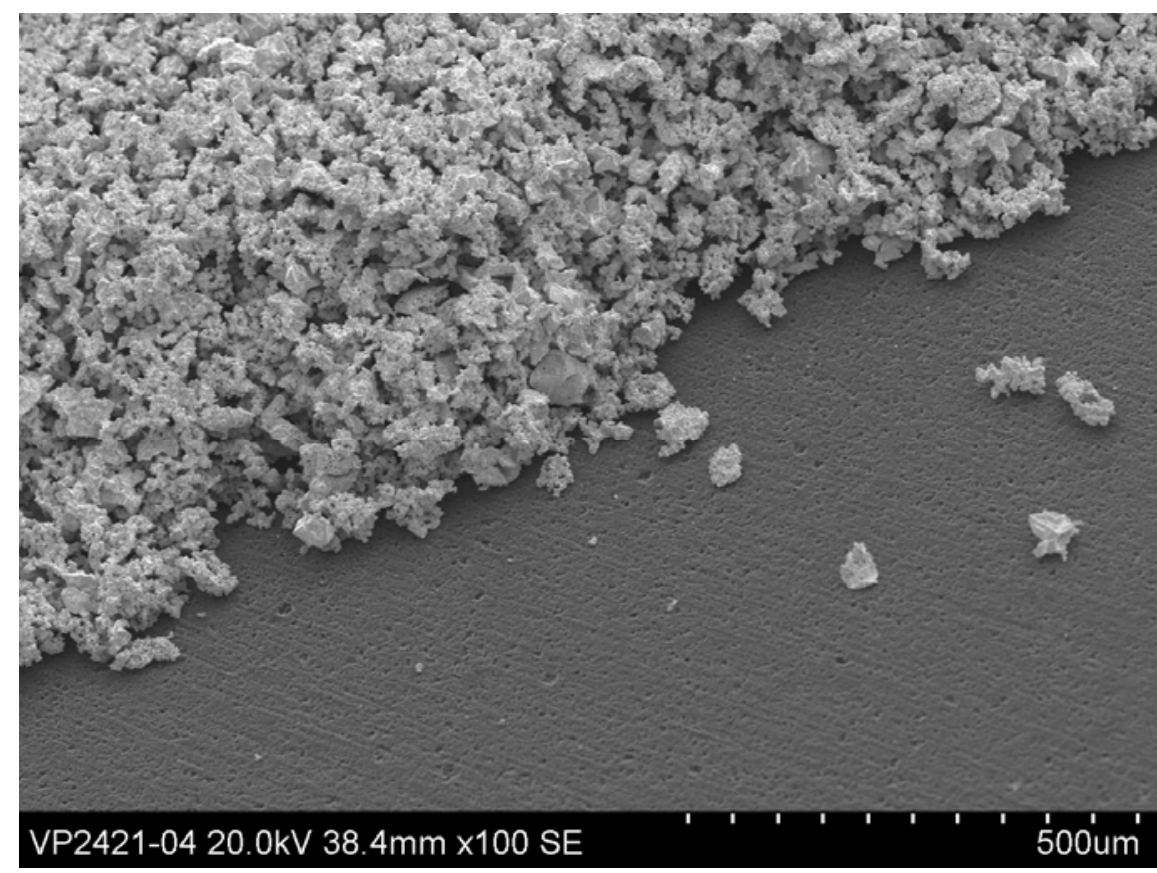

Figure 9. Secondary electron image (100X magnification) of POCO AXF$5 \mathrm{Q}$ graphite Pin \#3 showing residual iridium powder from lot 21, 012800, Jar A adhering to Pin face. 


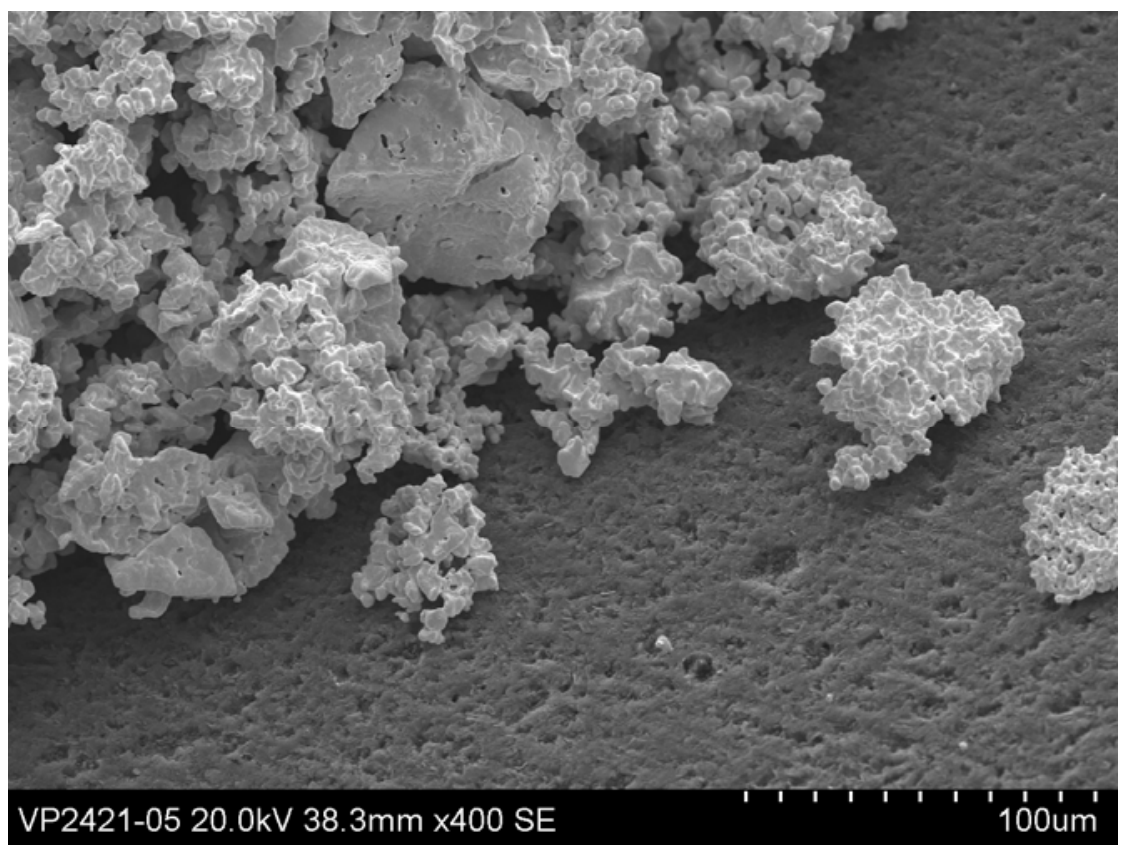

Figure 10. Secondary electron image (400X magnification) of POCO AXF$5 \mathrm{Q}$ graphite Pin \#3 showing residual iridium powder from lot 21, 012800, Jar A adhering to Pin face.

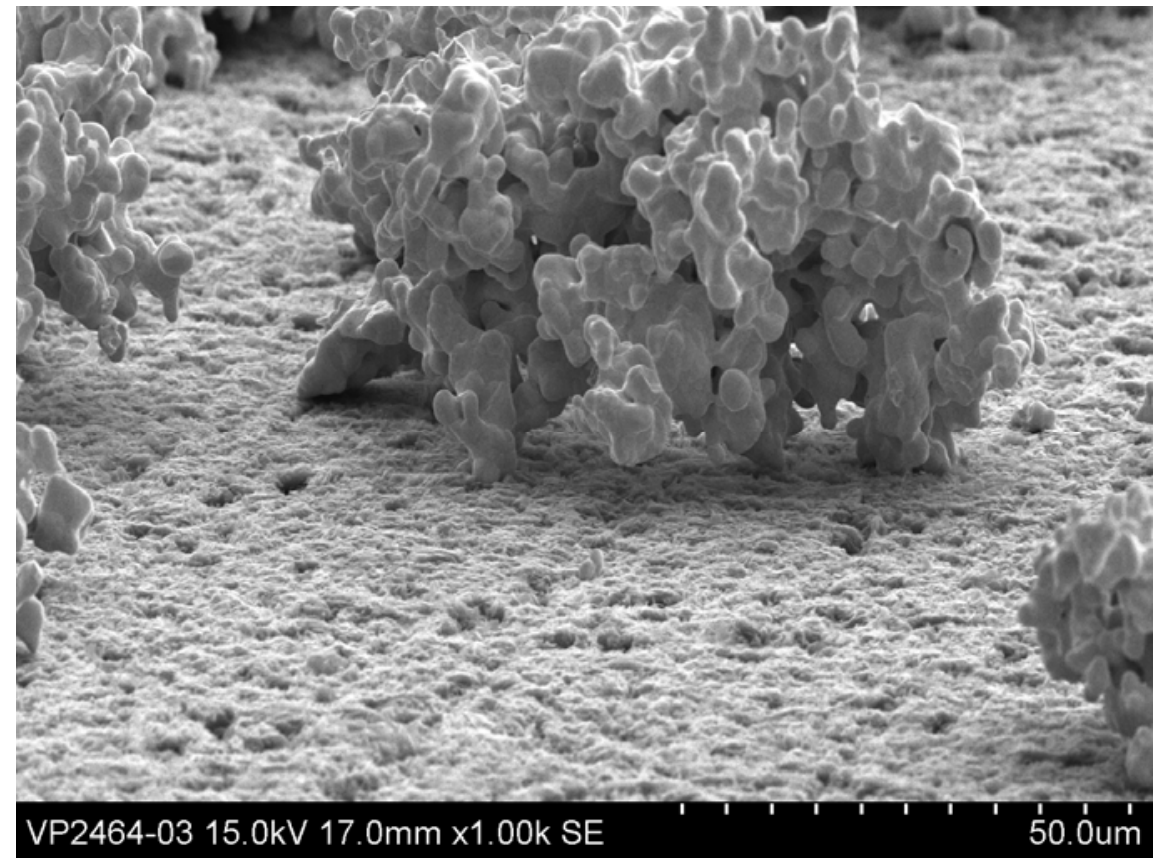

Figure 11. Secondary electron image (1000X magnification) of POCO AXF-5Q graphite Pin \#3 showing residual iridium powder from lot 21, 012800, Jar A adhering to Pin face. 


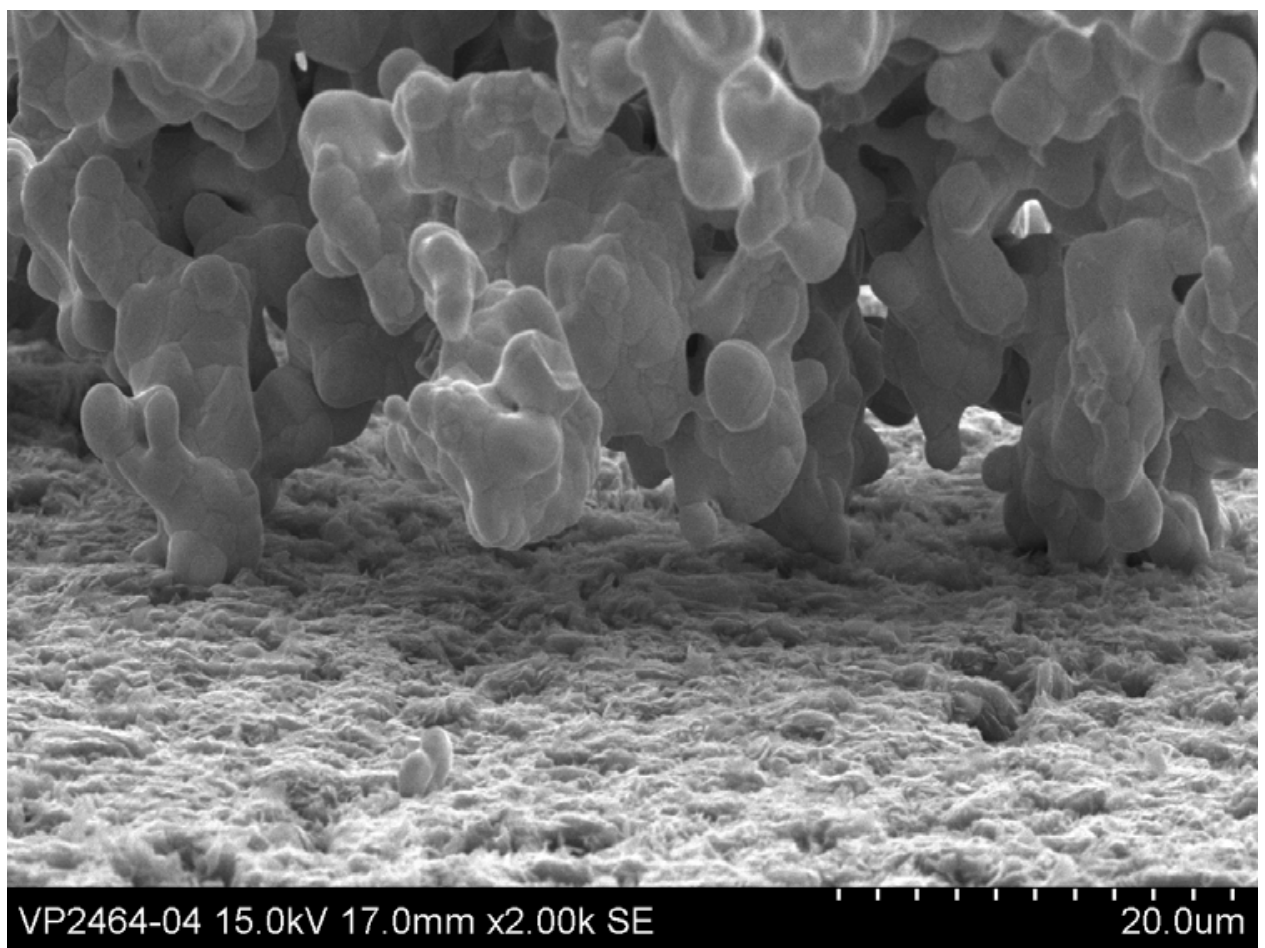

Figure 12. Secondary electron image (2000X magnification) of POCO AXF-5Q graphite Pin \#3 showing residual iridium powder from lot 21, 012800, Jar A adhering to Pin face.

\subsubsection{Metallurgical Destructive Test Sample Evaluations of Grit Blasted Versus Non-Grit Blasted Iridium Alloy Clad Vent Set Cup Surfaces}

Metallurgical evaluations were conducted to determine what, if any, grain size differences exist between grit blasted and non-grit blasted DOP-26 iridium alloy cup surfaces and if grit blasting imparts sufficient compressive cold work to induce abnormal grain growth during subsequent temperature exposures. Metallographic measurements indicated that grit blasting cold worked the outside cup surface to a depth of approximately $19 \mu \mathrm{m}$. Subsequent processing through the air burn-off $\left(635^{\circ} \mathrm{C} / 4 \mathrm{~h}\right)$ and vacuum outgassing $\left(1250^{\circ} \mathrm{C} / 1 \mathrm{~h}\right)$ operations was found to uniformly recrystallize the cold worked surface to produce grains with an average diameter of approximately $8.5 \mu \mathrm{m}$ (ASTM grain size number 11). Follow-on heat treatments at $1375^{\circ} \mathrm{C}, 1500^{\circ} \mathrm{C}$, and $1900^{\circ} \mathrm{C}$ for durations ranging from $1 \mathrm{~min}$ to $70 \mathrm{~h}$ yielded uniform grain sizes and no abnormal grain growth from grit blasting. Abnormal grain growth was noted at the $1500^{\circ} \mathrm{C}$ and $1900^{\circ} \mathrm{C}$ heat treatments in areas of cold work from excessive clamping during sample preparation. An ORNL technical report will be issued in FY 2010 describing this work. 


\subsection{IRIDIUM POWDER AND INVENTORY MANAGEMENT}

The purpose of this work is to manage an iridium inventory for all heat source contractors with emphasis on the significant quantities of iridium located at Los Alamos National Laboratory (LANL), INL, and ORNL and to maintain a no-change iridium inventory through an annual write-off of inventory and processing losses.

\subsubsection{Iridium Demand and Supply Schedule}

The demand and supply schedule, prepared for contingent planning purposes, presents a strategy to assess the availability of iridium for all improving and producing activities by projecting future demands. An adequate inventory needs to be maintained to meet the needs of the NASA space explorations and defense missions. Table 3 indicates that enough iridium will be available for these missions.

The first part of Table 3 shows the estimated production demand factors for prime blanks and foil. The schedule of produced blanks and foil represents the quantity and timing for delivery or storage at ORNL. The ingots from new material represent the quantity produced from new iridium powder to make either blanks or foil. These ingots must be produced on a timely basis to meet the lead-time requirement to produce and deliver or store the blanks and foil.

The production of blanks and foil produces recyclable iridium material that can be placed back into the production process at ORNL. A greater economic benefit is realized by using recycled material, since the need to purchase iridium powder from an outside vendor is reduced.

Refinable iridium scrap is also generated from the production of blanks and foil. This scrap is sent to a commercial refinery when a sufficient accumulation occurs at ORNL, funding is available for the refining, and it makes economic sense based on a comparison of refining costs to that of new material.

Process losses of iridium occur during the working of the material at ORNL, LANL, and INL. Losses also occur during the refining process. These inventory losses are written off annually.

The information contained within the table can be summarized as follows. There will be an adequate supply of iridium powder to produce the hardware for NASA space exploration and defense missions and $96.7 \mathrm{~kg}$ will remain at the beginning of FY 2013. 
Table 3. Demand and Supply Schedule Shows Factors and Provides Strategy to Ensure an Adequate Supply of Iridium Powder for NASA Space Explorations and Defense Missions

\begin{tabular}{|c|c|c|c|c|}
\hline \multirow{2}{*}{ Factors and strategy } & \multicolumn{4}{|c|}{ U. S. Government fiscal years } \\
\hline & FY 2009 & FY 2010 & FY 2011 & FY 2012 \\
\hline \multicolumn{5}{|c|}{ Production-demand factors } \\
\hline Produced blanks ${ }^{1}$ & 10 & 10 & 30 & 30 \\
\hline Ingots from new material & 0 & 0 & 0 & 1 \\
\hline Ingots from recyclable material & 0 & 0 & 0 & 0 \\
\hline Produced foil $\left(\mathrm{m}^{2}\right)$ & 0 & 0 & 0 & 0.5 \\
\hline \multicolumn{5}{|c|}{ Refining and process losses $(\mathrm{kg})$} \\
\hline Refining gain ( loss) & 0 & 0 & 0 & 0 \\
\hline Processing gain (loss) & 1.3 & $(1.5)$ & $(3.0)$ & $(3.0)$ \\
\hline \multicolumn{5}{|c|}{ Supply strategy $(\mathrm{kg})^{2}$} \\
\hline Beginning balance of powder & 120.0 & 119.7 & 117.7 & 115.7 \\
\hline Receipt of refined powder & 0 & 0 & 0 & 0 \\
\hline Receipt of purchased powder & 0 & 0 & 0 & 0 \\
\hline
\end{tabular}

${ }^{1}$ Estimate of maximum number of blanks

${ }^{2} \mathrm{FY} 2013$ beginning balance of powder is estimated to be $96.7 \mathrm{~kg}$.

\subsubsection{Annual Write-Off}

The annual FY 2009 write-off of iridium inventory was completed in May. A total of 0.7 $\mathrm{kg}$ of iridium was written off as a normal operating loss. The write-off appropriately reduced the non-fund iridium inventory. This $0.7 \mathrm{~kg}$ loss was considered a normal operating loss compared to the history of iridium losses during the past several years.

\subsubsection{Iridium Accountability Reviews}

The review at ORNL was conducted in April. The purpose of this review was to evaluate the accountability, physical inventory, and security of iridium at ORNL. It was concluded that the accountability, physical inventory, and security for the iridium was in place and operating in a proper manner. No recommendations were necessary. 
The review at LANL was conducted in July. The purpose of this review was to evaluate the accountability, physical inventory, and security of iridium at LANL. It was concluded that the accountability, physical inventory, and security for the iridium was in place and operating in a proper manner. No recommendations were necessary.

\subsection{WELDING}

\subsubsection{Russian Fuel Procurement and Radioactive Material Transport}

Support was provided to DOE-NE-34 for onsite surveillance at the Mayak Production Association during October 2008. This effort was to ensure processing and packaging of the material met the contract requirements and proper handling of the USA/9516/B(U)F85 .

This visit had been delayed from May 2008 due to the inability to obtain permission for onsite access. Analytical chemistry results were verified to be in compliance with contract prior to the site visit along with a proposed loading plan was reviewed to verify that the configuration met the requirements of USA/9516/B(U)F-85 Safety Analysis Report for Packaging, Certificate of Compliance and Certificate of Competent Authority. During this visit, on site access was granted for only the second week of the surveillance. Direct observation was conducted on secondary containment vessel loading and welding, nondestructive testing (radiography, helium leak, visual, and weld size gauging) results contamination smears, cask loading, and application of tamper indicating devices (TIDs). Independent review of all radiographs was also performed.

Two additional meetings were held with Mayak administration, including Sergey Baranov Mayak Director General, to review the current surveillance and future work plans.

Support was provided to INL concerning past uses, component fabrication, nondestructive test methods, and design intent, for the USA/9516/B(U)F-85 and USA/9904/B(U)F-85 packages. Support was also provided to Energy Solutions for review of -96 SARP for the 9516 packaging.

\subsubsection{CVS Production Welding Support}

Three procedures (GPHS-K-001, GPHS-K-9753, and GPHS-K-9754) were modified and approved following qualification of new weld procedures and operators.

During one production run of welding frit vent assemblies (FVAs) to vent cups, one weld exhibited cracking on the outside of the vent cup. Evaluation of this vent cup showed that the cracking was caused by aluminum contamination. An evaluation of the possible sources of metal contamination showed that the Ten Head Weld Positioner could generate metal fines when being rotated to welding position and abrasion of the aluminum alignment blocks when the fixture is installed or removed from the work table. Evacuation and backfilling of the chamber could cause sufficient air flow to distribute 
any contaminates to the components being welded. To eliminate both sources of contamination, a contract was placed to procure a slide table to eliminate fines generation when tooling in installed or removed from the work table. The Ten Head Weld Positioner was also redesigned to prevent fines generation during operation. Receipt of the slide table and modification of the Ten Head Weld Positioner will take place in FY 2010.

A mass flow meter was purchased to develop an alternate method of measuring flow rate of FVAs. The flow meter was coupled to a computer DAQ to record data. Further evaluation of flow measurements showed that air contamination could bias mass flow measurements which extended testing durations. A series of flow measurements were made on four FVAs with the approved method and mass flow to compare methods. Additionally both helium and nitrogen were used as testing gases to determine if an alternate gas may be used with the mass flow meter. Table 4 shows the initial measurements by both test methods and test gases. These results showed little difference by either test method or gas. Long term data will be generated in FY 2010 to further evaluate flow test methods.

Table 4. Flow Testing of FVAs

\begin{tabular}{|l|l|l|l|l|}
\hline \multirow{2}{*}{ FVA } & \multicolumn{2}{|l|}{ BUBBLE $^{\text {SIERRA MASS FLOW METER }}$} \\
\cline { 2 - 5 } & HELIUM $^{1}$ & NITROGEN $^{2}$ & HELIUM $^{3}$ & NITROGEN $^{4}$ \\
\hline 9752-05-5101 & 3.58 & 3.54 & 3.41 & 3.61 \\
& 3.56 & 3.55 & & 3.59 \\
& 3.57 & 3.56 & & 3.57 \\
\hline ATJ1 & 5.73 & 5.58 & 5.72 & 5.63 \\
& 5.79 & 5.58 & & 5.64 \\
& 5.79 & 5.58 & & 5.63 \\
\hline POCO4 & 10.47 & 10.40 & 10.29 & 10.30 \\
& 10.51 & 10.38 & & 10.39 \\
& 10.49 & 10.36 & & 10.37 \\
\hline POCO5 & 14.93 & 14.78 & 14.73 & 14.94 \\
& 14.96 & 14.74 & & 14.93 \\
& 14.93 & 14.78 & & 14.88 \\
\hline
\end{tabular}

\subsubsection{Weld Shield Qualification}

The welding procedure and three welding operators were qualified for the butt welding of integral weld shields in February 2009 per the Training Guidelines for the RPS program, GPHS-PGD-1. Figure 13 is a representative micrograph of a weld shield butt weld at the completion of weld development. Figure 14 is a photograph of a weldment produced during welding qualification. Welding procedure GPHS-K-3620, Rev. 4 was approved for use in March 2009. There are currently three operators qualified to perform butt welding of integral weld shields. 


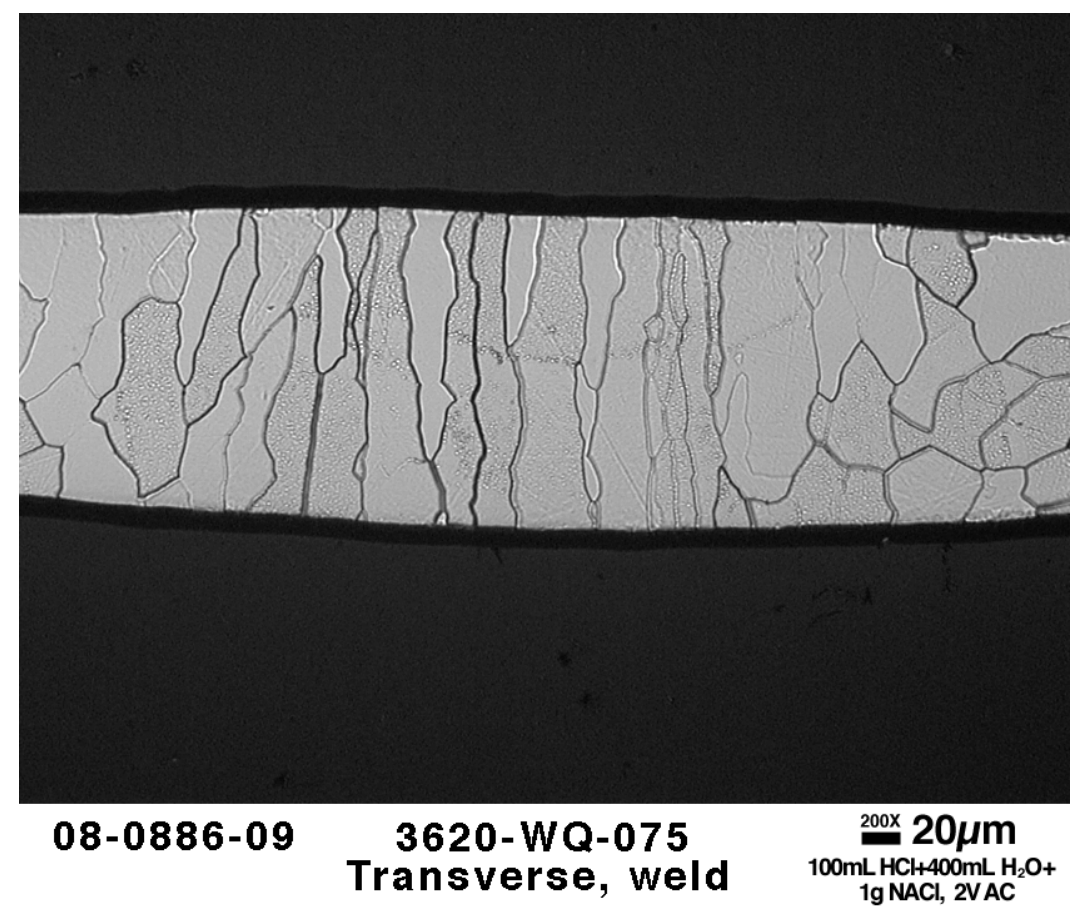

Figure 13. Cross section of weld shield butt weld

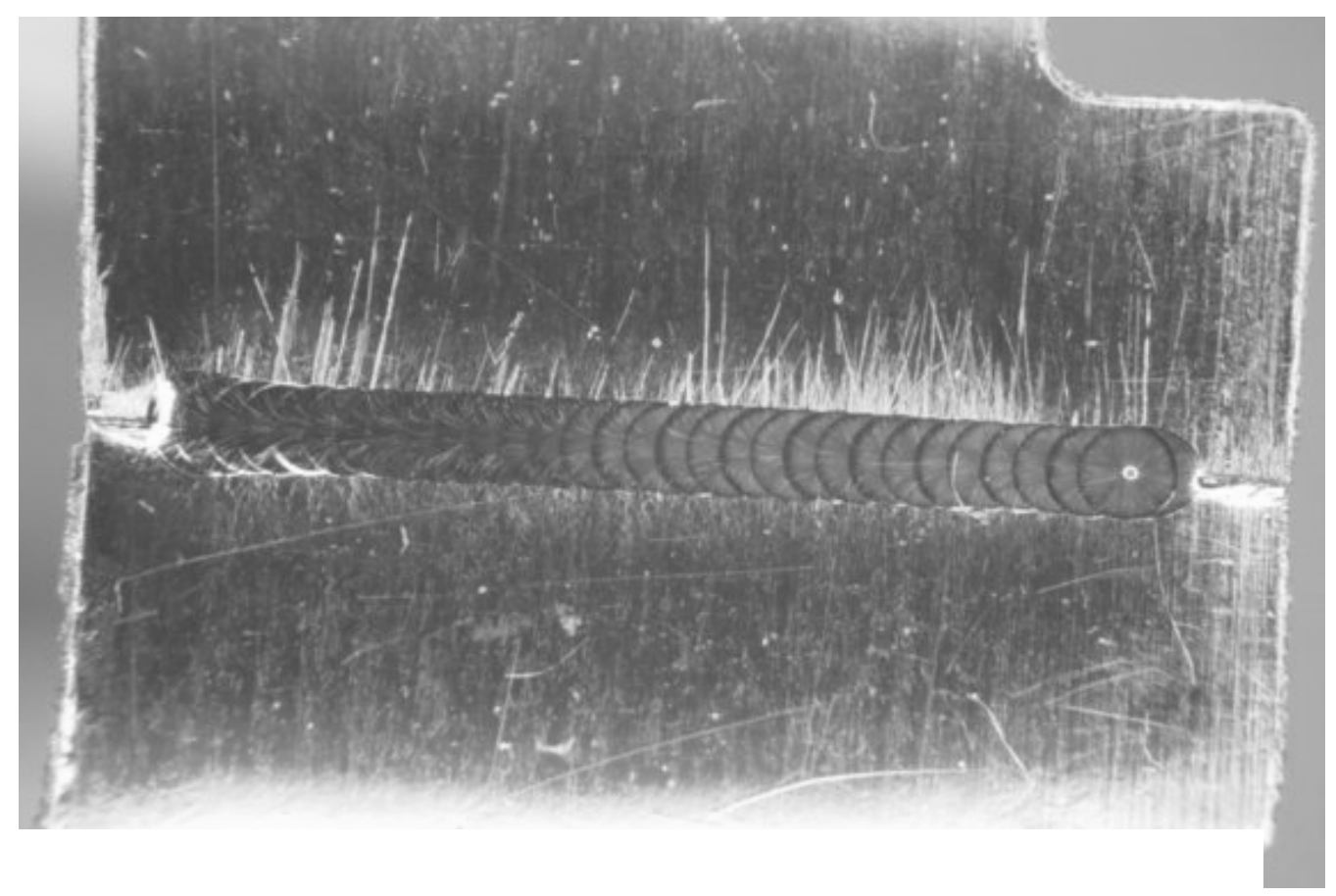

Figure 14. Top view of completed weld shield butt weld 


\subsubsection{Qualification of Electron Beam Operators}

The final welding qualification of welding operators, other than weld shield butt welding, was completed in December 2008. Two welding operators had been previously qualified during FY 2008. A third operator completed training on EB welding equipment and successfully completed qualification welding on waster sheets, FVA to vent cup, DC to vent cup, and weld shield to shield cup.

\subsubsection{FY 2009 Fuel Procurement}

No additional fuel procurement was completed during FY 2009 due to schedule delays. 


\section{BASE TECHNOLOGY TASKS}

\subsection{ALLOY CHARACTERIZATION}

\subsubsection{Introduction}

The objective of this task is to characterize the mechanical and metallurgical properties of metallic materials that are of interest to the RPS Program. Summarized below are the results of our activities during FY 2009.

\subsubsection{Effects of Grain Size and Temperature on the Ductility and Strength of DOP- 26 Iridium at a Low Strain Rate}

In support of the application of DOP-26 iridium as a fuel-cladding material in RTG, several studies have been conducted at the Oak Ridge National Laboratory to characterize the metallurgical and mechanical properties of DOP-26 iridium. These include measurements of the tensile impact ductility at a high strain rate of $\sim 10^{3} \mathrm{~s}^{-1}$ and temperatures of $500-1100^{\circ} \mathrm{C}$. These tensile impact studies were performed over a range of grain sizes (obtained by heat treatments at various temperatures). However, they provided only ductility values (since the tensile impact gun is not instrumented to measure loads at impact strain rates). Therefore, studies using both a servo-hydraulic machine and a screw-driven machine at lower strain rates, up to $\sim 10 \mathrm{~s}^{-1}$, were initiated to measure strength and ductility. During FY 2009 we investigated the influence of grain size on the strength and ductility of DOP-26 iridium at a strain rate of $\sim 10^{-3} \mathrm{~s}^{-1}$. A hightemperature anneal, $1 \mathrm{~h}$ at $1650^{\circ} \mathrm{C}$, expected to produce a grain size of $\sim 45 \mu \mathrm{m}$, was used in the current studies for comparison to earlier studies where the standard recrystallization anneal of $1 \mathrm{~h}$ at $1375^{\circ} \mathrm{C}$ was used, which results in a smaller grain size of $\sim 25 \mu \mathrm{m}$. The yield strengths for the two different heat treatments were found to be similar over almost the entire temperature range (77-1373 K), although some additional testing is needed at low temperatures to confirm the apparent lack of a grain size dependence. Above about $400^{\circ} \mathrm{C}$, the ultimate strengths are also quite similar. But at lower temperatures, there is considerable scatter in the ultimate strengths due to the strong work hardening rate and brittleness. Relatively small changes in the elongation to fracture can result in relatively large changes in the ultimate strength (unlike at elevated temperatures where work hardening is weak). Nevertheless, the results obtained in the present study indicate that there is not a strong grain-size dependence of strength and ductility at the low strain rate of $\sim 10^{-3} \mathrm{~s}^{-1}$, unlike at the high strain rate of $\sim 10^{3} \mathrm{~s}^{-1}$ where ductility is strongly grain-size dependent.

\subsubsection{Effects of Tantalum on the Tensile Impact Ductility and Fracture Behavior of DOP-26 Iridium}

Trace elements can have beneficial (e.g., Th, Ce, and W) or deleterious (e.g., Si) effects on the mechanical properties of iridium alloys. During FY 2009 we initiated an investigation into the effects of tantalum because, during CVS production, the DOP-26 iridium alloy is exposed to tantalum. Therefore, it is of interest to determine what effects accidental Ta contamination could have on the mechanical properties of DOP-26 iridium. 
Tantalum additions of 0.1 to $0.5 \mathrm{wt} \% \%$ were found to severely embrittle DOP-26 iridium when its grain size is around $45-55 \mu \mathrm{m}$, but only modestly when its grain size is smaller, around $17-23 \mu \mathrm{m}$. Consistent with this, Ta promotes brittle intergranular fracture at the larger grain sizes but not at the smaller grain sizes. Additional experiments are planned in the future to understand the mechanisms of this embrittlement and to determine the range of grain sizes and temperatures over which it could pose problems for the fueled clad.

\subsubsection{Evaluation of Silicon Contamination Effects in DOP-26 Iridium}

Following the discovery at LANL of elevated Si levels in some batches of plutonia fuel, ORNL was asked to evaluate what effects Si might have on the DOP-26 iridium fuel clad. We found that Si can have varying degrees of harmful effects on the metallurgical and mechanical properties of DOP-26 iridium. For example, at levels higher than 500 wppm, Si causes severe embrittlement by segregating to the grain boundaries where it displaces Th, increases the grain size, and forms a low melting eutectic. The embrittlement is less severe at lower Si levels (50 wppm), but the ductility is still measurably lower than that of DOP-26 containing no added silicon. Furthermore, even at this low level, Si segregated to the grain boundaries and increased grain growth. Silicon also lowered the weldability relative to that of production heats of DOP-26 iridium. The maximum allowable $\mathrm{Si}$ in the current specification for DOP-26 iridium blanks is 50 wppm. Since deleterious effects were identified even at this low level it is of interest to tighten the specification. To accomplish this, a few DOP-26 alloys with Si concentrations in the 15-25 wppm range are needed. If their metallurgical and mechanical properties can be shown to be similar to those of DOP-26 containing no added silicon, the allowable Si can then be lowered to $25 \mathrm{wppm}$. Unfortunately, it has not been possible to produce DOP-26 alloys containing these levels of silicon: the measured Si concentrations after melting and casting were either too low or too high. Therefore, we started to investigate alternative approaches of introducing $\mathrm{Si}$ into DOP-26 iridium. Several different approaches were tried during the last two years, including: (i) annealing in Si vapor, (ii) coating with a thin Si layer followed by annealing, (iii) solid state Ir-Si diffusion couples followed by annealing, (iv) annealing in vacuum in the presence of $\mathrm{SiO}_{2}$. These either produced no diffusion of Si into the iridium (e.g., in the case of annealing with $\mathrm{SiO}_{2}$ ) or, if there was introduction of $\mathrm{Si}$, it occurred in an extremely inhomogeneous manner (e.g., in the case of the diffusion couples). Iridium forms several different intermetallics with $\mathrm{Si}$, including $\mathrm{Ir}_{3} \mathrm{Si}_{2} \mathrm{Ir}_{3} \mathrm{Si}_{2}, \mathrm{IrSi}$, and several other lower-order silicides. These are formed at the Ir-Si interface and, because of the negligible solubility of Si in Ir, there is little solid state transport of $\mathrm{Si}$ into the underlying iridium. Additionally, the DOP-26 alloy contains Th, which also forms many silicides on the grain boundaries. These graded microstructures are not useful to simulate the behavior of DOP-26 uniformly alloyed with less than $50 \mathrm{wppm} \mathrm{Si}$. Therefore, it is concluded that future efforts should be focused on melting and casting approaches and attempts be made to produce DOP-26 containing controlled levels of $\mathrm{Si}$ in the 15-25 wppm range. 


\subsection{ORNL CHARACTERIZATION OF MIN-K TE-1400}

\subsubsection{Introduction}

ORNL was requested to perform additional mechanical testing in an effort to further evaluate the mechanical behavior of Min-K 1400 when subjected to a variety of conditions. Min-K 1400 is a high temperature load-bearing fibrous silica insulation that can be used to position, support and insulate an isotopic heat source within a thermoelectric generator housing. Heat source restraint is accomplished by compressively preloading pieces of Min-K between the housing and the heat source. The Min-K 1400 subsequently functions like a spring to store the preload in the form of potential energy, which resists in-line heat source motion and laterally restrains the heat source via friction.

The generator's long-term structural integrity is intimately coupled with preload, since unrestrained heat source motion can damage internal generator components and cripple performance. It is known, however, that Min-K 1400 is susceptible to load relaxation at its anticipated operating conditions. Additionally, complications due to a launch delay have necessitated the performance of additional testing to reduce risk due to unknowns and "soft spots" in currently available test data.

In particular, ORNL was requested to scope the assembly of test equipment and associated testing to determine the mechanical behavior of provided Min-K samples under various controlled environments and conditions as described below.

\subsubsection{Testing}

\subsubsection{Task 1. Changing Environments Testing}

The purpose of this testing is to validate the stress relaxation predictions made based on previously generated data from ORNL. Changes in temperature and strain will now be imparted on installed Min-K components due to storage requirements associated with program launch delays. Effects of these changes need to be evaluated through testing under various changing environmental conditions. Testing consists of preloading a specimen (disks 6 inches in diameter and 2 inches thick) to a prescribed level. After $\approx 100$ days a temperature change is implemented and the preload on the sample altered to simulate a move to cold storage. Following the temperature change, the displacement is held constant for another 50 to 100 days. At that point, another change in temperature and load is performed to simulate a change in environments for launch. The new conditions are then held constant for 10 to 20 days.

Seven of these types of test have been initiated. Several have been ended prematurely due to furnace platen failures. The longest running test (shown below in Figure 15) has been running for over 2,760 hours and has gone through the first of the two "changing environments" events. Two other tests (currently running for over 690 and 330 hours, respectively) are also still on-going. 


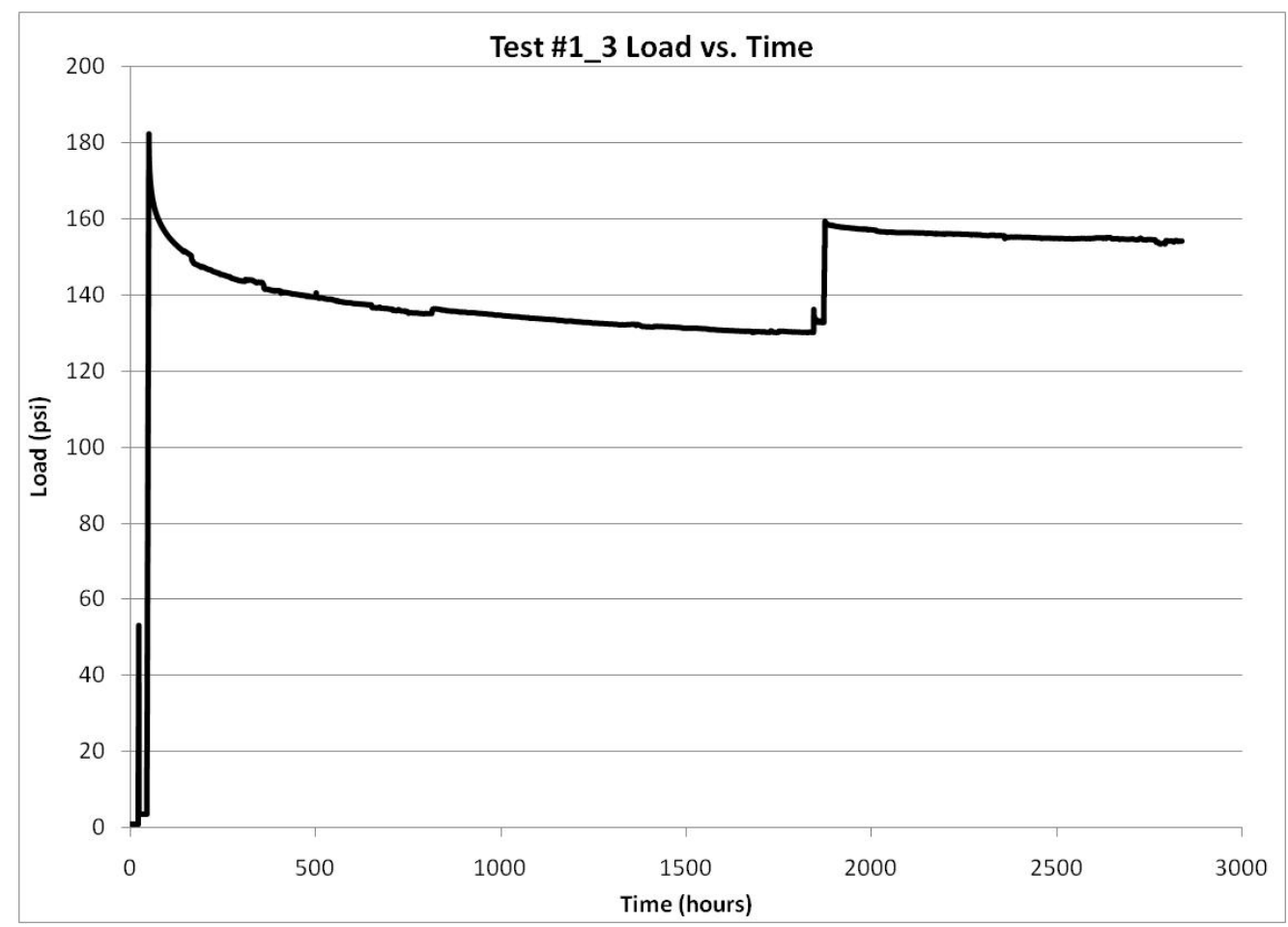

Figure 15. Changing Environments Test \#1_3.

\subsubsection{Task 2. Lateral Load Testing}

The purpose of this testing is to provide information on the "friction factor" used for estimates of Min-K behavior. This is hoped to allow a higher "threshold" value to be used, thereby increasing margins and decreasing uncertainty.

The set-up for this testing consists of a metal plate (with pyramoidal surface features) sandwiched between two constrained pieces of Min-K with a tangential load applied on top of the stack (see Figure 16). A lateral load is then applied to the center metal plate to remove it from the stack while monitoring all applied loads. A furnace is incorporated into the test set-up to allow for the performance of testing at elevated temperatures. A picture of the original equipment proposed for modification to accommodate this test setup is shown in Figure 17. 


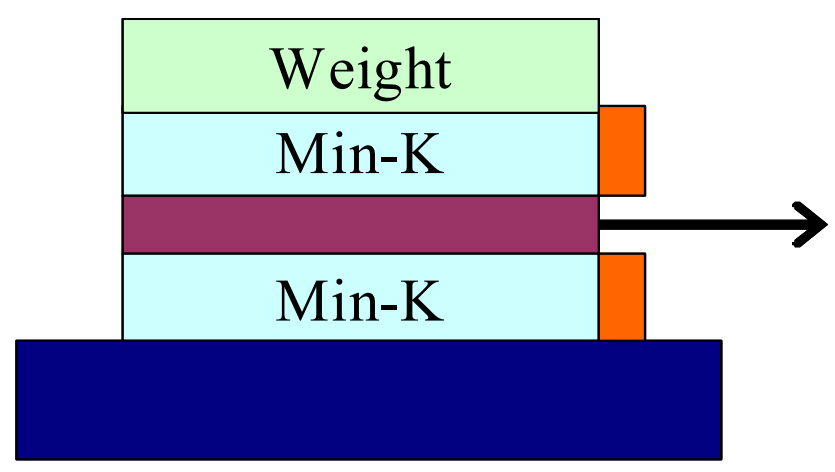

Figure 16. Lateral load test set-up.

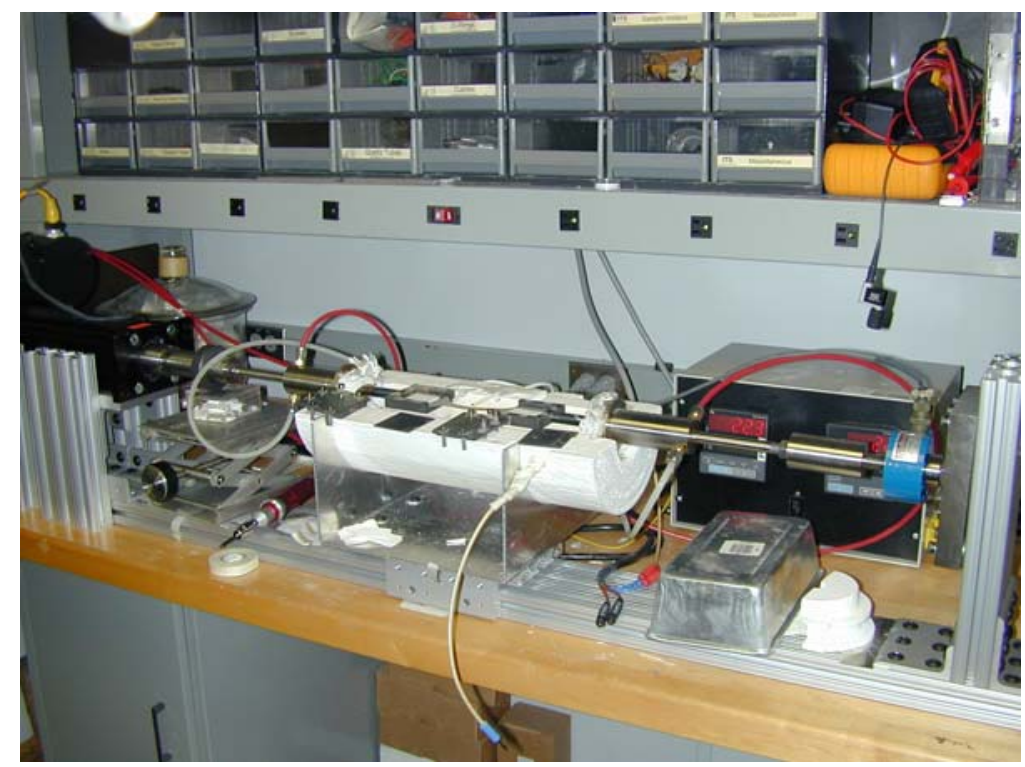

Figure 17. Test system for modification to accomplish lateral load testing.

The final test set-up is shown in Figure 18. This system allows for application of the axial load through movement of a mechanical actuator and application of lateral loads through a turnbuckle system. Validation of the test system was performed at room temperature and elevated temperature testing has been initiated. Sample results of testing are shown below in Figure 19. 


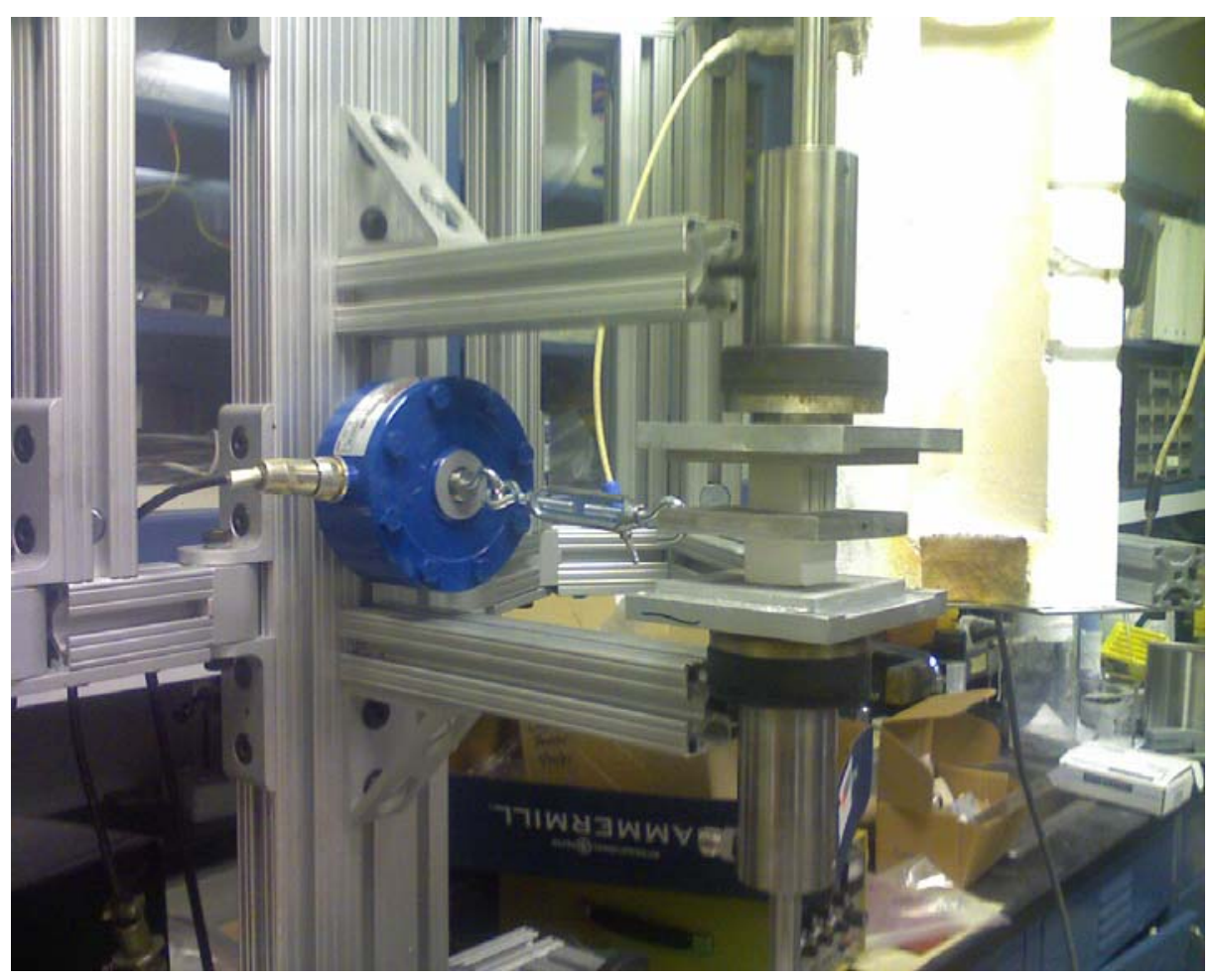

Figure 18. Lateral load test set-up (shown without furnace assembly).

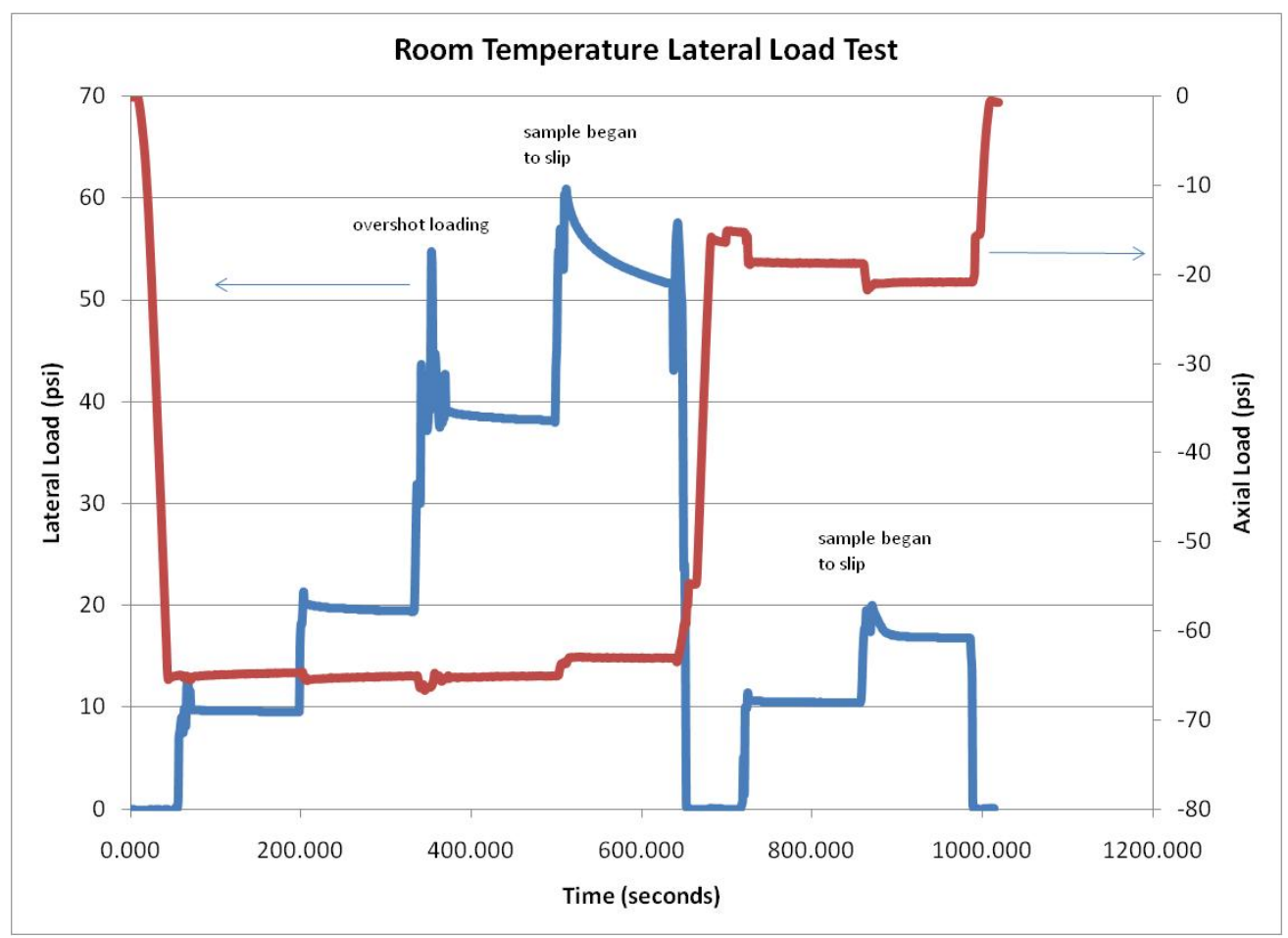

Figure 19. Room temperature lateral load test data. 


\subsubsection{Task 3. Isothermal Stress Relaxation Testing}

The purpose of this testing is to provide additional information on the isothermal stress relaxation behavior of Min-K at intermediate temperatures in the range of $400-500^{\circ} \mathrm{C}$. As found through previous testing, the behavior of Min-K transitions from "lower temperature behavior" to "higher temperature behavior" at these temperatures.

The stress-relaxation behavior of Min-K was determined under isothermal conditions using disks 6 inches in diameter and 2 inches thick. The test procedure consisted of subjecting the cylindrical test specimens to a fixed strain after reaching a desired preload. The load was then monitored and recorded for the duration of the test. Tests were performed in dry helium using an electromechanical testing machine equipped with a cylindrical furnace and an environmental chamber. Four tests have been completed at temperatures of 450 and $500^{\circ} \mathrm{C}$. An example of data from testing is shown in Figure 20.

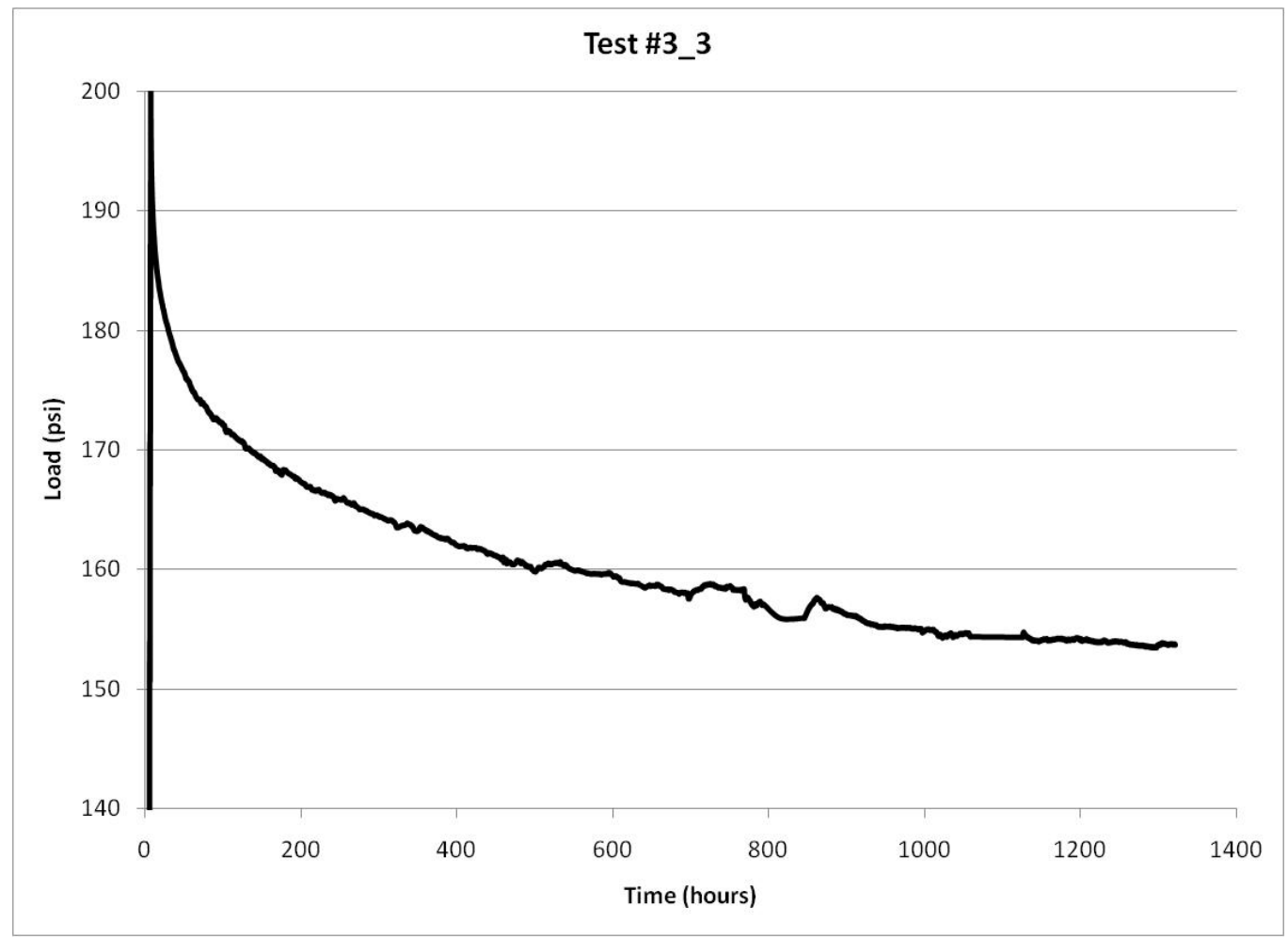

Figure 20. Isothermal stress relaxation testing at $500^{\circ} \mathrm{C}$. 


\subsubsection{Additional Work}

Additionally, ORNL has participated in weekly teleconferences with Rocketdyne and Teledyne and has hosted two visits by Rocketdyne personnel to review testing set-ups and initial results. Weekly and monthly progress reports have also been submitted. 
INTERNAL DISTRIBUTION
1. E. P. George
2. J. G. Hemrick
3. J. M. Holladay
4. J. S. Ivey
5-7. J. F. King
8. R. G. Miller
9. E. K. Ohriner
10. G. R. Romanoski
11. G. B. Ulrich
12. ORNL Laboratory Records_-OSTI

\section{EXTERNAL DISTRIBUTION}

13-19. U. S. DEPARTMENT OF ENERGY, NE-34/Germantown Building, 1000 Independence Avenue S. W., Washington, District of Columbia 20585-1290
W. A. Bohne
O. W. Lowe
D. A. Cairns-Gallimore
L. L. Rutger
A. K. Caponiti
W. S. Yoon

20. DEPARTMENT OF ENERGY, Oak Ridge Office, Building 4500N, Oak Ridge, TN 37831

S. R. Martin, Jr., Mail Stop 6269

21. IDAHO NATIONAL LABORATORY, P. O. Box 1625, Idaho Falls, ID 83415
K. L. Lively

22. LOS ALAMOS NATIONAL LABORATORY, P. O. Box 1663, NMT-9, MS E502, Los Alamos, NM 87545

C. E. Van Pelt

23-24. ORBITAL SCIENCES CORPORATION, INC., 20030 Century Blvd., Suite 102, Germantown, MD 20874
R. T. Carpenter
E. A. Skrabek

25. URS Washington Division, P. O. Box 5388, Aiken, SC 29804-5388

M. O. Smith 